\title{
Atmospheric Mining in the Outer Solar System: Resource Capturing, Exploration, and Exploitation
}

Bryan Palaszewski

Glenn Research Center, Cleveland, Ohio 


\section{NASA STI Program . . . in Profile}

Since its founding, NASA has been dedicated to the advancement of aeronautics and space science. The NASA Scientific and Technical Information (STI) Program plays a key part in helping NASA maintain this important role.

The NASA STI Program operates under the auspices of the Agency Chief Information Officer. It collects, organizes, provides for archiving, and disseminates NASA's STI. The NASA STI Program provides access to the NASA Technical Report Server-Registered (NTRS Reg) and NASA Technical Report ServerPublic (NTRS) thus providing one of the largest collections of aeronautical and space science STI in the world. Results are published in both non-NASA channels and by NASA in the NASA STI Report Series, which includes the following report types:

- TECHNICAL PUBLICATION. Reports of completed research or a major significant phase of research that present the results of NASA programs and include extensive data or theoretical analysis. Includes compilations of significant scientific and technical data and information deemed to be of continuing reference value. NASA counter-part of peer-reviewed formal professional papers, but has less stringent limitations on manuscript length and extent of graphic presentations.

- TECHNICAL MEMORANDUM. Scientific and technical findings that are preliminary or of specialized interest, e.g., "quick-release" reports, working papers, and bibliographies that contain minimal annotation. Does not contain extensive analysis.
- CONTRACTOR REPORT. Scientific and technical findings by NASA-sponsored contractors and grantees.

- CONFERENCE PUBLICATION. Collected papers from scientific and technical conferences, symposia, seminars, or other meetings sponsored or co-sponsored by NASA.

- SPECIAL PUBLICATION. Scientific, technical, or historical information from NASA programs, projects, and missions, often concerned with subjects having substantial public interest.

- TECHNICAL TRANSLATION. Englishlanguage translations of foreign scientific and technical material pertinent to NASA's mission.

For more information about the NASA STI program, see the following:

- Access the NASA STI program home page at http://www.sti.nasa.gov

- E-mail your question to help@sti.nasa.gov

- Fax your question to the NASA STI Information Desk at 757-864-6500

- Telephone the NASA STI Information Desk at 757-864-9658

- Write to:

NASA STI Program

Mail Stop 148

NASA Langley Research Center Hampton, VA 23681-2199 


\section{Atmospheric Mining in the Outer Solar System: Resource Capturing, Exploration, and Exploitation}

Bryan Palaszewski

Glenn Research Center, Cleveland, Ohio

Prepared for the

49th Joint Propulsion Conference and Exhibit

cosponsored by the AIAA, ASME, SAE, and ASEE

San Jose, California, July 14-17, 2013

National Aeronautics and

Space Administration

Glenn Research Center

Cleveland, Ohio 44135 
Level of Review: This material has been technically reviewed by technical management.

Available from

NASA STI Program

Mail Stop 148

NASA Langley Research Center

Hampton, VA 23681-2199
National Technical Information Service 5285 Port Royal Road Springfield, VA 22161

$703-605-6000$

This report is available in electronic form at http://www.sti.nasa.gov/ and http://ntrs.nasa.gov/ 


\title{
Atmospheric Mining in the Outer Solar System: Resource Capturing, Exploration, and Exploitation
}

\author{
Bryan Palaszewski \\ National Aeronautics and Space Administration \\ Glenn Research Center \\ Cleveland, Ohio 44135
}

\section{Summary}

Atmospheric mining in the outer solar system (AMOSS) has been investigated as a means of fuel production for high-energy propulsion and power. Fusion fuels such as helium $3\left({ }^{3} \mathrm{He}\right)$ and hydrogen can be wrested from the atmospheres of Uranus and Neptune and either returned to Earth or used in-situ for energy production. ${ }^{3} \mathrm{He}$ and hydrogen (deuterium, etc.) were the primary gases of interest, with hydrogen being the primary propellant for nuclear thermal solid core and gas core rocket-based atmospheric flight. A series of analyses were undertaken to investigate resource capturing aspects of AMOSS. These analyses included the gas capturing rate, storage options, and different methods of direct use of the captured gases. Additional supporting analyses were conducted to illuminate vehicle sizing and orbital transportation issues. While capturing ${ }^{3} \mathrm{He}$, large amounts of hydrogen and helium $4\left({ }^{4} \mathrm{He}\right)$ are produced. With these two additional gases, the potential exists for fueling small and large fleets of additional exploration and exploitation vehicles. Additional aerospacecraft or other aerial vehicles (UAVs, balloons, rockets, etc.) could fly through the outer-planet atmosphere to investigate cloud formation dynamics, global weather, localized storms or other disturbances, wind speeds, the poles, and so forth. Deep-diving aircraft (built with the strength to withstand many atmospheres of pressure) powered by the excess hydrogen or ${ }^{4} \mathrm{He}$ may be designed to probe the higher density regions of the gas giants.

\section{Nomenclature}

$\begin{array}{ll}{ }^{3} \mathrm{He} & \text { helium } 3 \\ { }^{4} \mathrm{He} & \text { helium (or helium 4) } \\ \text { AMOSS } & \text { atmospheric mining in the outer solar system } \\ \text { delta-V } & \text { change in velocity }(\mathrm{km} / \mathrm{s}) \\ \text { GPS } & \text { Global Positioning System } \\ \text { ISRU } & \text { In-Situ Resource Utilization } \\ I_{\text {sp }} & \text { specific impulse (s) } \\ M_{\mathrm{p}} & \text { propellant mass } \\ \text { MT } & \text { metric tons } \\ \text { NTP } & \text { nuclear thermal propulsion } \\ \text { NTR } & \text { nuclear thermal rocket } \\ \text { UAV } & \text { unmanned aerial vehicle }\end{array}$

\section{Atmospheric Mining in the Outer Solar System}

Atmospheric mining of the outer solar system (AMOSS) is one of the options for creating nuclear fuels, such as ${ }^{3} \mathrm{He}$, for future fusion-powered exploration vehicles or powering reactors for Earth's planetary energy. Uranus's and Neptune's atmospheres would be the primary mining sites, and robotic vehicles would wrest these gases from the hydrogen-helium gases of those planets. Preliminary estimates 
of the masses of the mining vehicles have been created (Refs. 1 to 8), and additional supporting vehicles may enhance the mining scenarios (Refs. 9 to 20). Storing the mined gases at automated bases on outerplanet moons was conceived to ease the storage requirements on interplanetary transfer vehicles (that would return the cryogenic gases to Earth or deliver them to other destinations).

\section{Resource Capturing Studies}

Studies of the gas capture rate and its influence on mining time in the atmosphere were conducted. Aerospacecraft cruisers have been identified as a "best" solution for atmospheric mining (Refs. 1 to 8). To power these vehicles, atmospheric hydrogen gas would be liquefied and used as a rocket propellant for the ascent to orbit. A nuclear gas-core rocket is a likely candidate for the cruiser (Figure 1, Refs. 17 to 20). Gaseous or liquid hydrogen would be used to power the engines during atmospheric mining operations. Helium $3\left({ }^{3} \mathrm{He}\right)$ would be separated from the atmospheric hydrogen, and helium (helium 4, ${ }^{4} \mathrm{He}$ ) would be captured, liquefied, and stored as a payload that would be returned to orbit. Table I and Figure 2 provide the amount of ${ }^{3} \mathrm{He}$ in the outer-planet atmospheres (Ref. 1). Figure 3 and Figure 4 show the mining time versus the capture rate for Uranus and Neptune, respectively (Ref. 1). A 500-kg payload of ${ }^{3} \mathrm{He}$ is captured during the mining time.

Figure 5 and Figure 6 provide the sizing of the gas-core-powered vehicles and a comparison of the solid-core and gas-core vehicle options, respectively (Refs. 1 and 2). The relatively low thrust-to-weight ratio of the nuclear engines may necessitate the use of a more advanced gas-core nuclear engine over the solid-core nuclear thermal propulsion (NTP). Although the gas-core engine is likely more attractive for mining missions that require a return to orbit, other smaller nuclear thermal engines will be more applicable to atmospheric exploration missions that do not require orbital access.

AMOSS can be a powerful tool in extracting fuels from the outer planets and allow fast human and robotic exploration of the solar system. Preliminary designs of aerospacecraft with gas-core rocket nuclear engines for mining the outer planets have been developed (Refs. 1 and 2). The analyses showed that gascore engines can reduce the mass of such aerospacecraft mining vehicles very significantly: from 72 to 80 percent reduction over NTP solid-core-powered aerospacecraft mining vehicles. Although this mass reduction is important in reducing the mass of the overall mining system, the complexity of a fissioning plasma gas-core rocket is much higher than the more traditional solid-core NTP engines. Additional analyses were conducted to calculate the capture rates of hydrogen and ${ }^{4} \mathrm{He}$ during the mining process. Very large masses of hydrogen and ${ }^{4} \mathrm{He}$ are produced every day during the often lengthy process of ${ }^{3} \mathrm{He}$ capture and gas separation. Figure 7 shows the mass of hydrogen needed for the gas-core rocket and the potentially excess hydrogen captured every day (Ref. 1). Typically, these very large (excess) additional fuel masses can dwarf the requirements needed for hydrogen capture for ascent to orbit. Thus, the potential for fueling small and large fleets of additional exploration and exploitation vehicles exists. Aerial vehicle designs can take on many configurations. Additional aerospacecraft or other unmanned aerial vehicles (UAVs), balloons, rockets, and so forth, could fly through the outer-planet atmospheres for activities such as global weather observations, localized storm or other disturbance investigations, wind speed measurements, and polar observations. Deep-diving aircraft (built with the strength to withstand many atmospheres of pressure) powered by the excess hydrogen or ${ }^{4} \mathrm{He}$ may be designed to probe the higher density regions of the gas giants.

Based on these analyses, there will likely be several possible future ways to effectively use the gases of the outer planets for exciting and scientifically important atmospheric exploration missions. The analyses focused on Uranus and Neptune, as these planets offer vast reservoirs of fuels that are more readily accessible than those from Jupiter and Saturn (as Uranus and Neptune require lower energies needed to attain orbit and present less danger from powerful atmospheric lightning) and, with the advent of nuclear fusion propulsion, may offer us the best option for fast interplanetary travel and the first practical interstellar flight. 


\section{Atmospheric Exploration Missions and Vehicles}

This section will discuss the issues of future atmospheric exploration and the vehicles that may conduct that exploration.

\section{Uranus and Neptune - Clouds and Dynamism}

A series of exploration missions for the Uranus and Neptune clouds and overall atmosphere would yield many great discoveries of their dynamics. Appendix A provides a number of cloud images from Earth-based (Keck) and space-based (Hubble) telescopes and spacecraft (Voyager). Appendix B notes the cloud changes of many years of observations (Refs. 21 to 29). As an example, when the Voyager spacecraft flew by Neptune in 1989, it photographed the Great Dark Spot at $15^{\circ}$ south latitude. Imaging conducted by the Hubble Space Telescope in 1991, 1996, and 1998 revealed that the Spot had completely disappeared, and no other clouds or disturbances were seen on or near that latitude (Refs. 25 to 29). At Uranus, the cloud structures were revealed with Earth-based telescopes and the Hubble Space Telescope in the 1990s and 2000s, whereas previous Voyager flyby images (from 1986) showed no clouds (Refs. 21 to 24). Gathering data on the clouds' dynamics and the related atmospheric wind speeds can be accomplished with in situ UAV flights. Measuring wind velocities at varying altitudes can lead to improved understanding of the lifetime of the cloud features noted in the telescopic observations of the atmosphere. Also, atmospheric sampling may reveal the best places or safest places for ${ }^{3} \mathrm{He}$ or hydrogen mining, or both. Thus, with the right array of probes and UAVs, exploration and exploitation of the atmospheric phenomena and resources can be simultaneously conducted.

\section{Atmospheric Exploration Vehicles}

A series of UAV and probe concepts were identified for atmospheric exploration. Table II provides the classes of probes and UAVs that can significantly augment future atmospheric exploration. Probes that use free fall or parachutes as they take data in the atmosphere are the first and most mature option. The Galileo Probe shown in Figure 8 (Refs. 30 and 31) is the baseline for many future atmospheric probe missions. A more aggressive approach to probe- or UAV-based exploration is the rocket assisted probe. As it can take many hours to access the deeper parts of the atmosphere (Ref. 32), a rocket assist to accelerate the probe to deep depths was considered. In addition to this, a rocket return was also conceived. Of course, high-pressure atmospheric flight operation of such vehicles will be a major challenge. Table III shows the ranges of masses for the probes and UAVs. The mass of the vehicles may be high based on the structure and wall thicknesses to withstand many atmospheres of pressure. Unique designs using pulsed detonation engines have been conceived, and such high-pressure detonation engines may be crucial to any future designs. Alternatively, balloons may be inflated to allow rapid ascent of the probe to higher altitudes. Balloons for rising to higher attitude may be a lower mass option than the rocket return, but a high-speed option for gaining altitude may be essential (for escaping high winds, wind shear, etc.), favoring the rocket return option. Taking advantage of more traditional UAV designs will also provide many operational benefits. Remote-sensing instruments on subsonic winged UAVs can potentially provide extensive data sets on outer-planet winds, cloud dynamics, and cloud formation. References 33 to 41 provide a range of applicable UAV designs and engine options.

Short-term observations (of several hours) can be accomplished with atmospheric entry probes that enter and then begin parachuting to lower altitudes. After a Galileo-class probe's atmospheric entry, it would slow to Mach 1 and deploy a parachute, sending back data for approximately $60 \mathrm{~min}$ (Ref. 30). Alternatively, the probe can be cut free of the parachute, and the lower altitudes can be attained more quickly in free fall. Figure 9 depicts the descent time for atmospheric probes exploring Uranus's and Neptune's atmosphere (Ref. 32). 
As noted in Reference 32,

"The times to descend to a given pressure level are shown in Figures 7(a) and 7, for Uranus and Neptune, respectively. The maximum time boundary is associated with a complete descent on the parachute as shown by the upper descent profile in the figures. Descent times to a pressure level of 200 bar on the parachute are about $5.5 \mathrm{hr}$ in the Uranus atmosphere and $4.4 \mathrm{hr}$ in the Neptune atmosphere. To descend to 400 bar will require $8 \mathrm{hr}$ at Uranus and $7 \mathrm{hr}$ at Neptune. These times are very large compared to with the actual descent time for the Galileo Probe at Jupiter (of $1 \mathrm{hr}$ ). The Galileo Descent Module was designed to reach a pressure level of about 10 to 20 bar before either the system fails or the communications are terminated.

The principal design problems associated with long descent times for Uranus and Neptune are: (1) maintaining the line of sight communications between the UAV or aerospacecraft and the probe for such a long period and (2) providing sufficient power during the long descent."

A UAV for AMOSS can be used as a data relay for the deep probes to cover their descent, which can take many hours. With nuclear atmospheric gas-powered UAVs, the relay and exploration functions can be completed by two complementary vehicles. One UAV will fly near the top of the atmosphere while the other conducts the deeper atmospheric surveys. Figure 10 shows the line-of-sight data transmission visibility geometry (Ref. 32). As the complementary UAVs will both be in the atmosphere, the transmission visibility issues will be ameliorated.

Figure 11, Figure 12, and Figure 13 provide a series of UAV configuration options: supersonic and subsonic (Refs. 36 and 37). Atmospheric gases are very attractive fuel for future UAV nuclear engines (Refs. 38 to 41). A ramjet UAV was investigated for operation on the Jovian atmosphere (Refs. 39 and 40). Figure 13 illustrates the nuclear ramjet (Refs. 39 to 42). The ramjet design is based on a small nuclear reactor called MITEE (Refs. 39 to 41). The engine inlet takes in the outer-planet atmospheric gases, feeds it to the reactor, and the reactor heats the gases and expands them through a nozzle for propulsion. Engine masses for the reactors are noted in Table IV (Refs. 38 to 41). Final designs must be based on specific configurations and the pressure field during the deep atmospheric flight.

The mass of each of the rocket-assisted UAVs was predicted for a range of vehicle delta-V values. Total UAV delta-V values were selected at 1,5 , and $10 \mathrm{~km} / \mathrm{s}$. Figure 14 and Figure 15 are for the $1 \mathrm{~km} / \mathrm{s}$ delta- $\mathrm{V}$ cases, Figure 16 and Figure 17 represent the cases for the $5-\mathrm{km} / \mathrm{s}$ delta- $\mathrm{V}$ values, and Figure 18 and Figure 19 show the results for UAVs with a $10-\mathrm{km} / \mathrm{s}$ delta-V capability. The vehicle dry mass (tank dry mass, without propellant) range was 0 to $10000 \mathrm{~kg}$. This mass range was selected to accommodate a range of dry mass values for a wide range of expected atmospheric pressures. More detailed analyses are needed to assess the specific masses for specific configurations. Tankage dry mass fractions were set at 2 and 10 percent of the total propellant mass (or 0.02 and $\left.0.10 M_{\mathrm{p}}\right)$. The engine specific impulse $\left(I_{\mathrm{sp}}\right)$ was selected to represent a nuclear engine at an $I_{\mathrm{sp}}$ of $900 \mathrm{~s}$. The UAV payload mass was $1000 \mathrm{~kg}$. For a $1-\mathrm{km} / \mathrm{s}$ delta-V UAV, a tankage mass of $0.10 M_{\mathrm{p}}$, and a $10000-\mathrm{kg}$ dry mass, the mass is approximately $12530 \mathrm{~kg}$. For $10-\mathrm{km} / \mathrm{s}$ delta-V, a tankage mass of $0.10 M_{\mathrm{p}}$, and a $10000-\mathrm{kg}$ dry mass, the mass is approximately $44450 \mathrm{~kg}$. For example, the $10 \mathrm{~km} / \mathrm{s}$ delta-V UAVs would have a capability of $1 / 2$ orbital speed and may allow simultaneous measurements with two of more UAVs on opposite sides of the planet. More detailed mission analyses can lead to specific mission selections for polar or more equatorial exploration flights or multivehicle campaigns.

\section{Supporting Analyses and Observations}

In addition to the capturing studies, reviews of outer-planet spacecraft design issues were initiated. A list of the issues to be addressed is noted below 
- Mission planning

- Cryogenic fuel storage issues

- Cryogenic dust (outer-planet moons, ice migration), mass concentrations (mascons) on the moons, and so forth

- Global Positioning System (GPS) vehicles in outer-planet orbits for navigation

- Observational satellite for outer-planet weather monitoring, diverting cruisers from harm

Also, Appendix B illuminates some of the issues to be analyzed. Appendix C contains gas and shock properties for a hydrogen-helium atmosphere ( 85 percent hydrogen and 15 percent helium by volume), and Appendix D provides some data of detonation engines operating in extremely high-pressure environments.

\section{Concluding Remarks}

Atmospheric mining at Uranus and Neptune can allow for the production of fuels for significant exploration and exploitation missions. While capturing helium $3\left({ }^{3} \mathrm{He}\right)$, large amounts of hydrogen and helium $4\left({ }^{4} \mathrm{He}\right)$ are produced. With these two additional gases, the potential for fueling small and large fleets of additional exploration and exploitation vehicles exists. Additional aerospacecraft or other aerial vehicles (unmanned aerial vehicles (UAVs), balloons, rockets, etc.) could fly through the outer-planet atmospheres, for global weather observations, localized storm or other disturbance investigations, wind speed measurements, polar observations, etc. Deep-diving UAV aircraft (built with the strength to withstand many atmospheres of pressure) powered by the excess hydrogen or ${ }^{4} \mathrm{He}$ may be designed to probe the higher density regions of the gas giants. Both nuclear ramjet and other rocket-powered probes were suggested. As there are powerful wind shear forces in the atmosphere, a compact ramjet UAV may be a best choice. The high aspect ratio and flexibility of a low-subsonic UAV may lead to serious damage during its flight due to wind shear.

The mass of the rocket-assisted UAVs was predicted for a range of vehicle delta-V values. For a $1 \mathrm{~km} / \mathrm{s}$ delta-V UAV, the highest mass is approximately $12530 \mathrm{~kg}$. For $10 \mathrm{~km} / \mathrm{s}$, the largest mass was approximately $44450 \mathrm{~kg}$. The $10 \mathrm{~km} / \mathrm{s}$ delta-V UAVs would have a $1 / 2$ orbital speed capability, and may allow simultaneous measurements with each on opposite sides of the planet. Issues of storing the large caches of propellants not needed for the orbital ${ }^{3} \mathrm{He}$ deliveries must be addressed. Small or large cryogenic hydrogen and helium tank farms in the atmosphere may be a solution. As the production rate and the amount of hydrogen and helium are high, the tank farms may have a similar configuration to the large aerospacecraft that carry the ${ }^{3} \mathrm{He}$ to orbit. 
TABLE I.-FRACTION OF ${ }^{3} \mathrm{He}$ IN OUTER-PLANET ATMOSPHERES

\begin{tabular}{|l|c|c|}
\cline { 2 - 3 } \multicolumn{1}{c|}{} & Uranus & Neptune \\
\hline Amount of ${ }^{3} \mathrm{He}$ in ${ }^{4} \mathrm{He}$ & $1.00 \times 10^{-4}$ & $1.00 \times 10^{-4}$ \\
\hline Amount of ${ }^{4} \mathrm{He}$ in atmosphere & 0.152 & 0.19 \\
\hline Amount of ${ }^{3} \mathrm{He}$ in atmosphere & $1.52 \times 10^{-5}$ & $1.90 \times 10^{-5}$ \\
\hline
\end{tabular}

TABLE II.-PROBE AND UNMANNED AERIAL VEHICLE (UAV) CLASSES

\begin{tabular}{l} 
Probes in free fall (no parachutes) \\
\hline Probes (with parachutes) \\
\hline Probes with rocket booster for accelerated attainment of low altitude (deep probe) \\
\hline Probes with rocket (booster) return for return to high altitude \\
\hline UAV (long persistence) \\
\hline Mining aerospacecraft (long persistence)
\end{tabular}

TABLE III.-PROBE AND UNMANNED AERIAL VEHICLE (UAV) MASS REGIMES

\begin{tabular}{|l|c|}
\hline \multicolumn{2}{|c|}{ Exploration UAV size ranges } \\
\hline Probe design & $\begin{array}{c}\text { Mass, } \\
\text { MT }\end{array}$ \\
\hline Free fall & 1 to 10 \\
\hline Parachute & 1 to 10 \\
\hline Rocket boost & 10 to 100 \\
\hline Rocket return & 10 to 1000 \\
\hline Long duration, subsonic & 10 to 1000 \\
\hline Aerospacecraft (mining) & 100 to 10000 \\
\hline
\end{tabular}

TABLE IV.-UNMANNED AERIAL

VEHICLE (UAV) NUCLEAR ENGINE MASSES AND THRUST LEVELS (REFS. 38 TO 41)

\begin{tabular}{|l|c|c|}
\hline \multicolumn{1}{|c|}{ Engine } & $\begin{array}{c}\text { Mass, } \\
\mathrm{kg}\end{array}$ & $\begin{array}{c}\text { Thrust, } \\
\text { lbf }\end{array}$ \\
\hline MITEE & 200.0 & 14000 \\
\hline Nuclear thermal rocket (NTR) & 2223.5 & 15000 \\
\hline
\end{tabular}




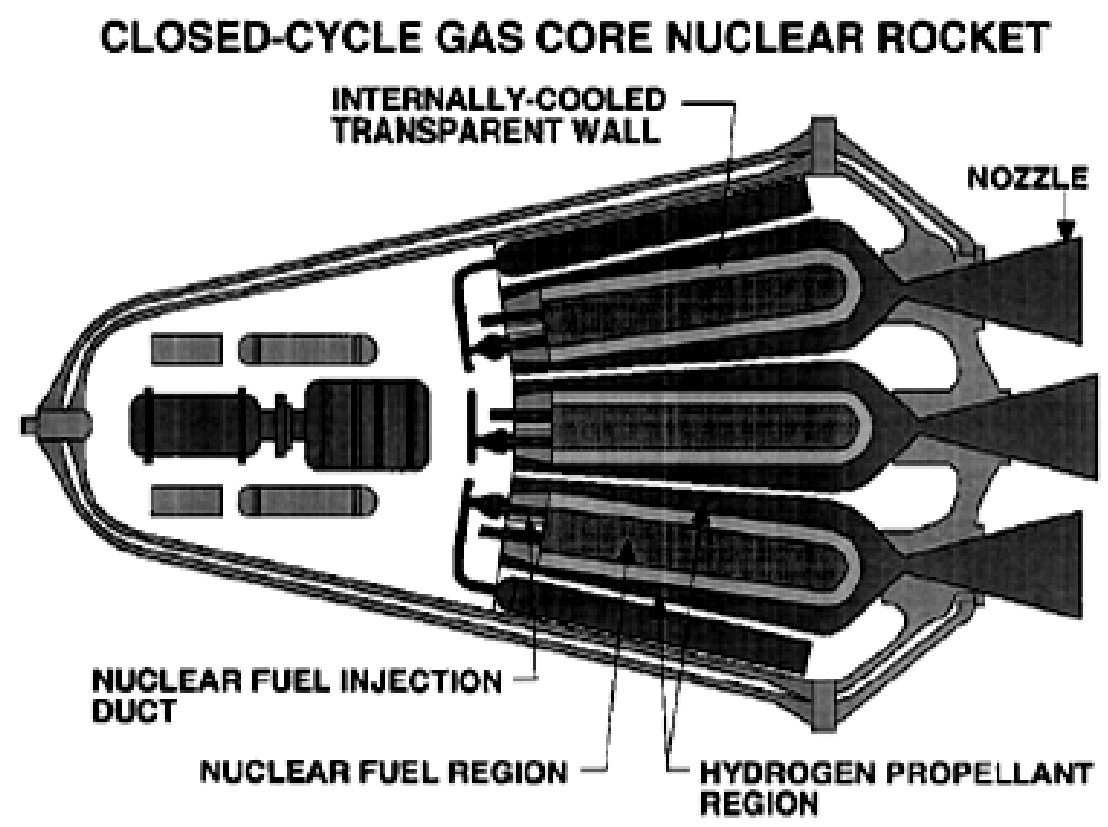

Figure 1.-Gas-core propulsion for cruiser (from Refs. 1 and 9).

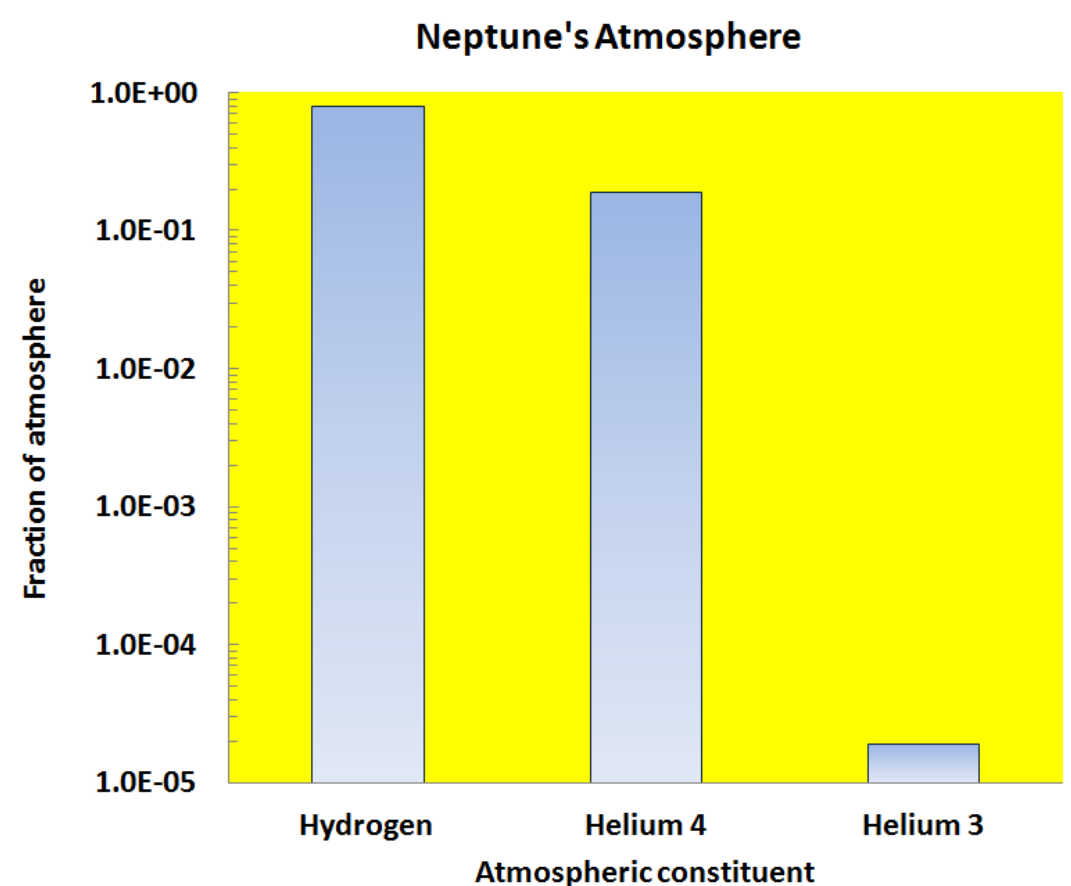

Figure 2.-Fractions of captured atmospheric gases for Neptune (from Ref. 1). 


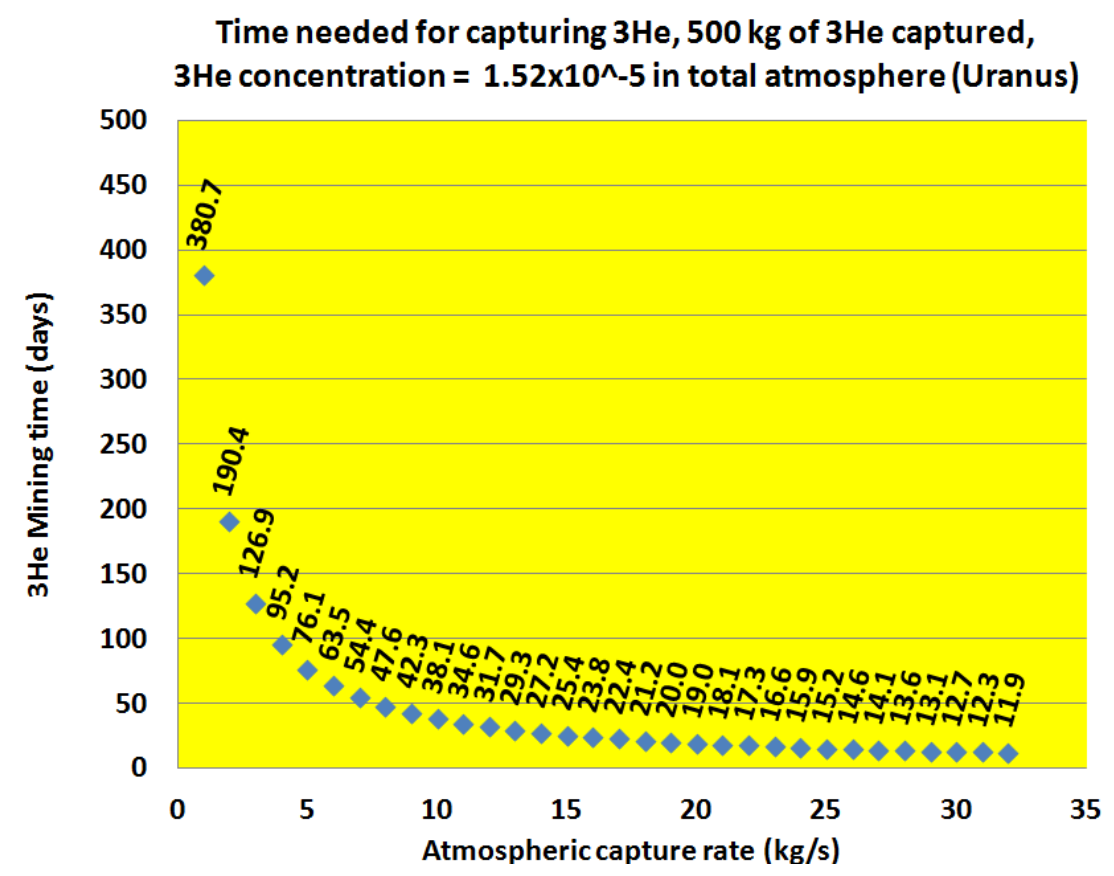

Figure 3.-Mining time versus capture rate for Uranus (Ref. 1).

Time needed for capturing $3 \mathrm{He}, 500 \mathrm{~kg}$ of $3 \mathrm{He}$ captured, $3 \mathrm{He}$ concentration $=1.9 \times 10^{\wedge}-5$ in total atmosphere $($ Neptune $)$

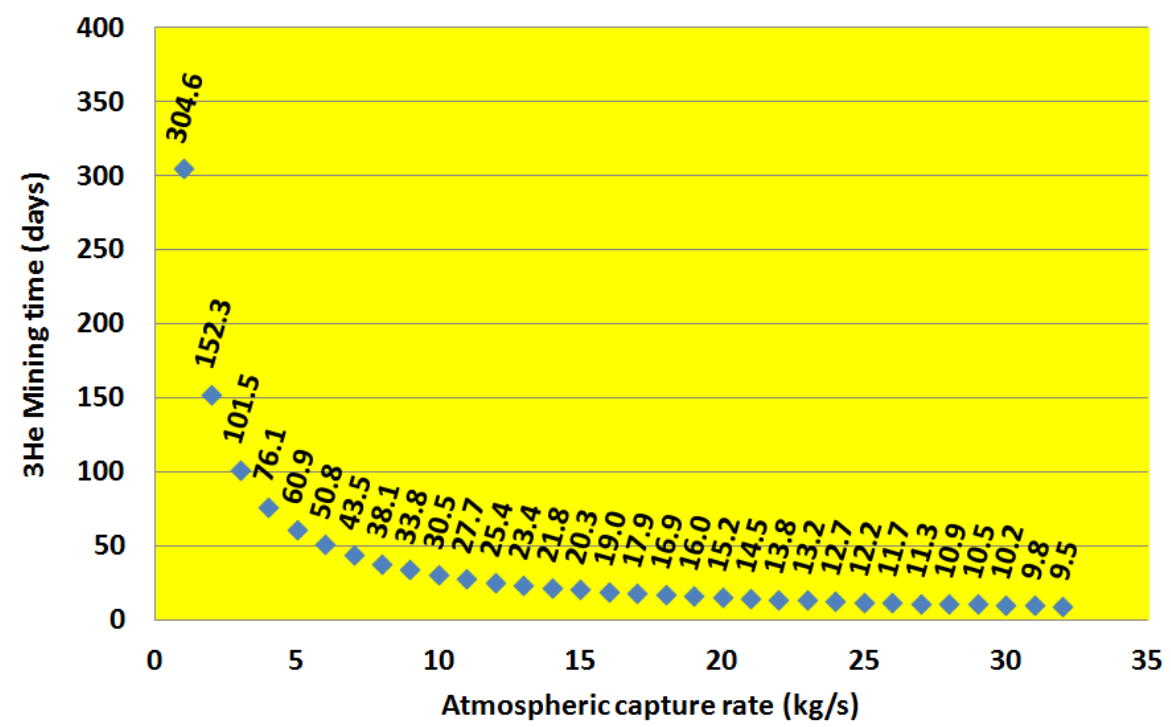

Figure 4.-Mining time versus capture rate for Neptune (Ref. 1). 
Nuclear Aerospacecraft,

Gas Core, 1,800-s Isp, 20-km/s delta-V capability,

1,000-kg payload

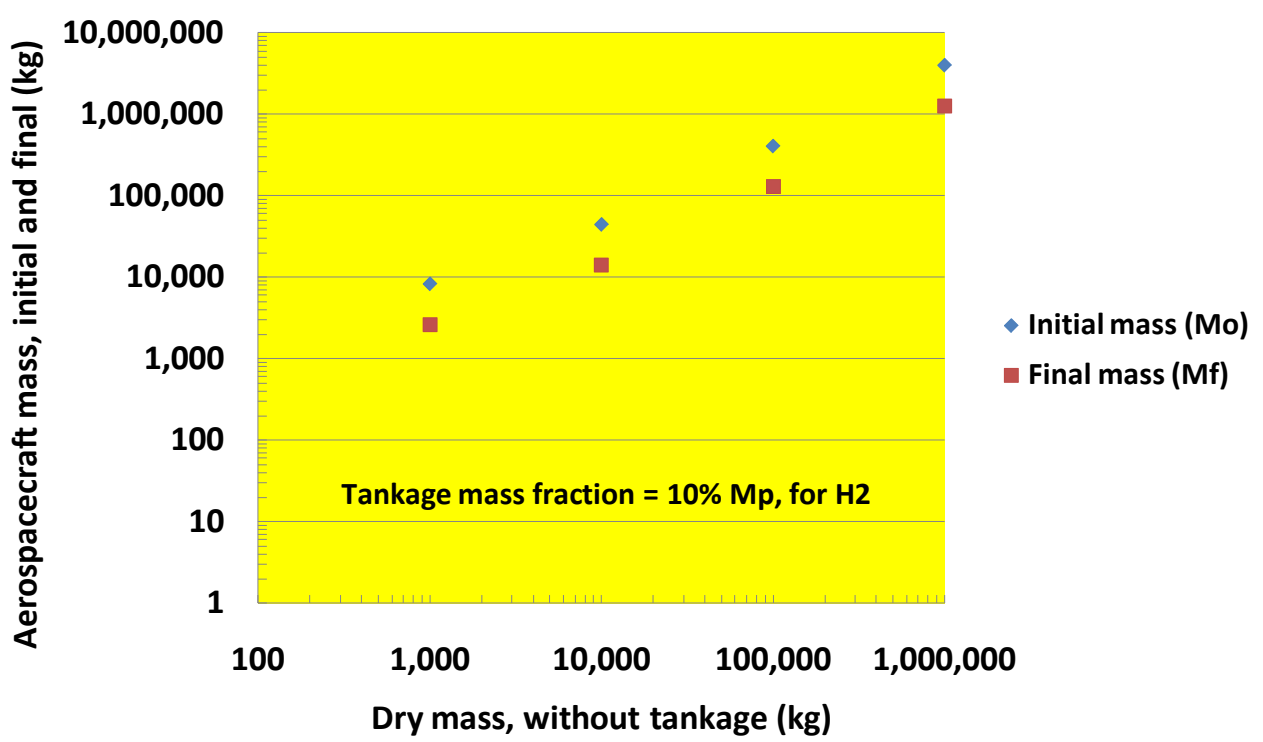

Figure 5.-Aerospacecraft mass, 1800-s $I_{\mathrm{sp}}$, Tankage mass $=10$ percent $M_{\mathrm{p}}$ for $\mathrm{H}_{2}$, representative of gas core nuclear propulsion (Ref. 1).

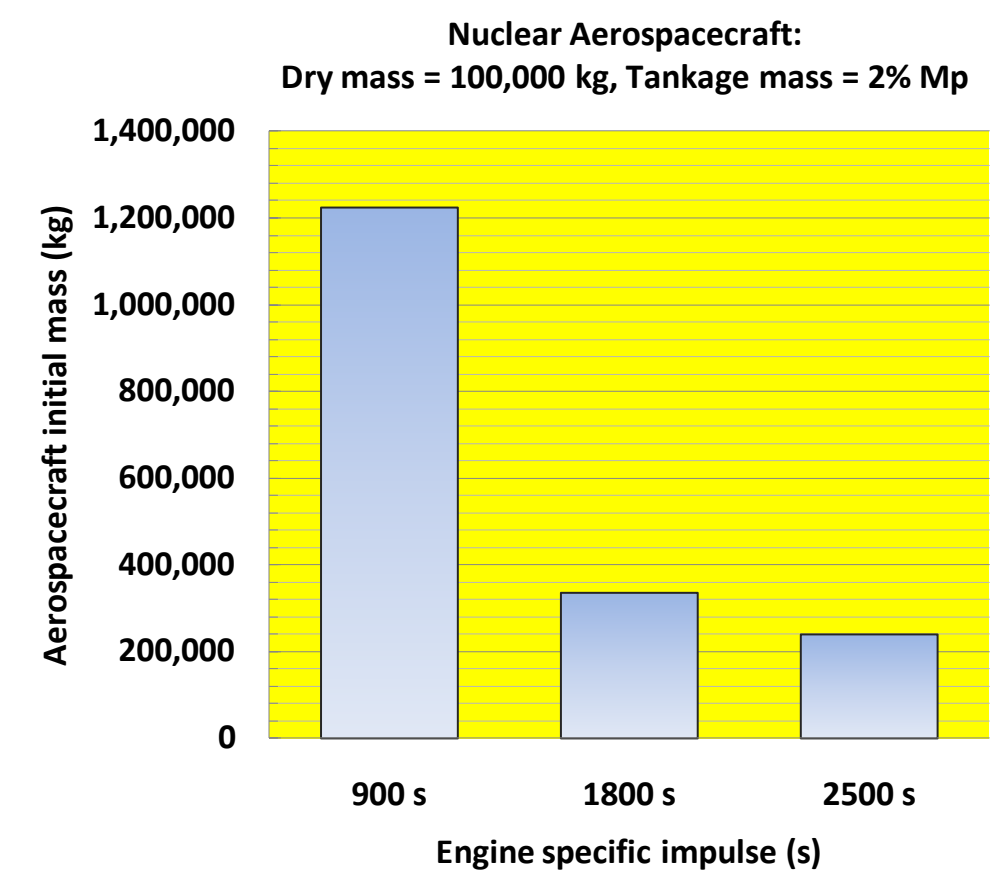

Figure 6.-Nuclear thermal propulsion: solid-core and gas-core vehicle mass comparison, $100000 \mathrm{~kg}$ dry mass, 2 percent $M_{\mathrm{p}}$ for $\mathrm{H}_{2}$ (Ref. 1). 
AMOSS $3 \mathrm{He}$ mining time and hydrogen capturing requirements,

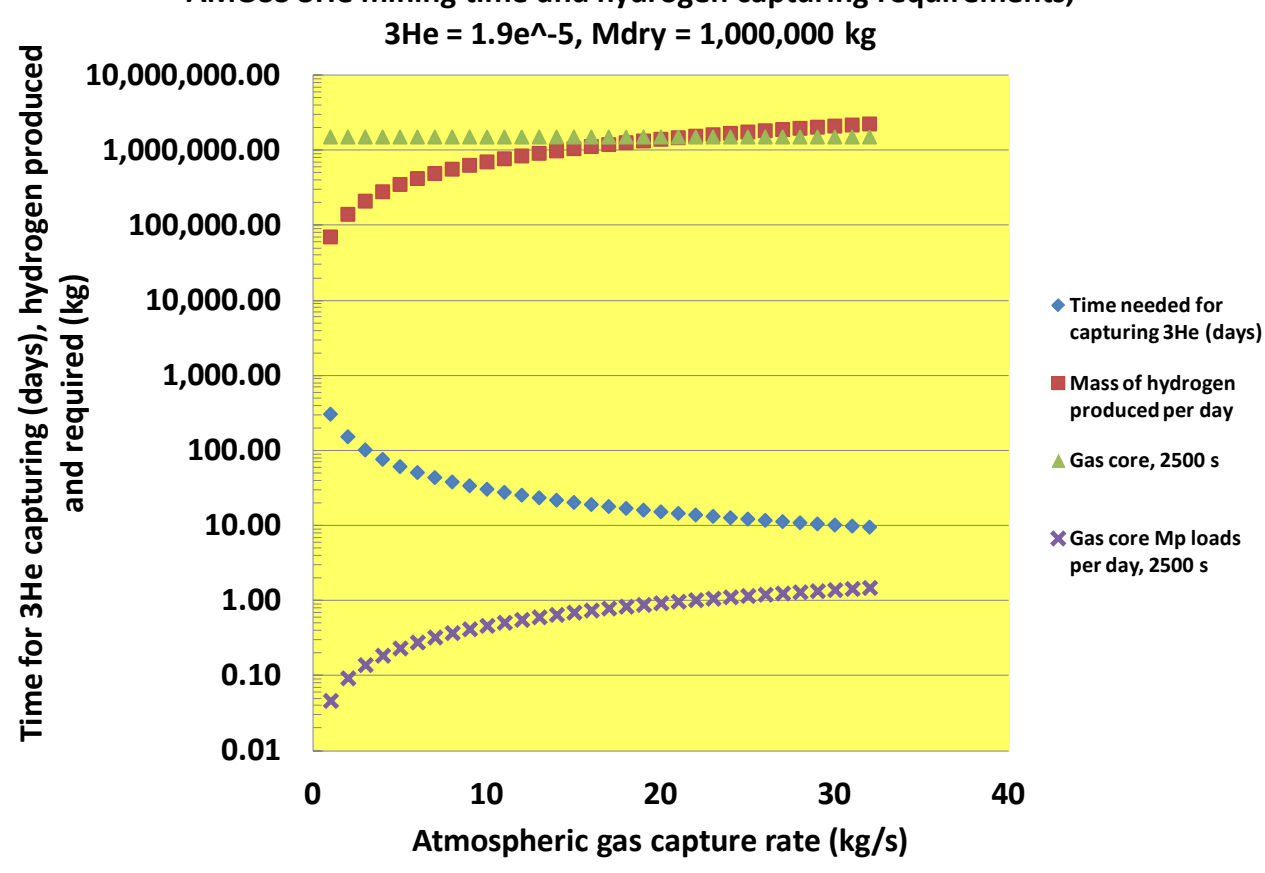

Figure $7 .-{ }^{3} \mathrm{He}$ mining time and hydrogen capture (mass per day) versus atmospheric gas capture rate for Neptune (Ref. 1).

\section{Galileo Probe Physical Properties and Key Scalability Challenges}

\begin{tabular}{|c|c|c|}
\hline Item / Subsystem & $\begin{array}{l}\text { Mass } \\
(\mathrm{kg})\end{array}$ & $\begin{array}{l}\text { Mass } \\
\text { Subtotals (kg) }\end{array}$ \\
\hline \multicolumn{2}{|l|}{ Deceleration Module } & 221.8 \\
\hline Forebody heat shield & 152.1 & \\
\hline Afterbody heat shield & 16.7 & \\
\hline Structure & 29.2 & \\
\hline Parachute & 8.2 & \\
\hline Separation hardware & 6.9 & \\
\hline Harness & 4.3 & \\
\hline Thermal control & 4.4 & \\
\hline \multicolumn{2}{|l|}{ Descent module } & 117.1 \\
\hline $\begin{array}{l}\text { Communications } \\
\text { subsystem }\end{array}$ & 13.0 & \\
\hline C\&DH subsystem & 18.4 & \\
\hline Power subsy stem & 13.5 & \\
\hline Structure & 30.0 & \\
\hline Harness & 9.1 & \\
\hline Thermal control & 4.3 & \\
\hline Science instruments & 28.0 & \\
\hline Separation hardware & 0.8 & \\
\hline \multicolumn{2}{|l|}{ Probe Total } & 338.9 \\
\hline
\end{tabular}
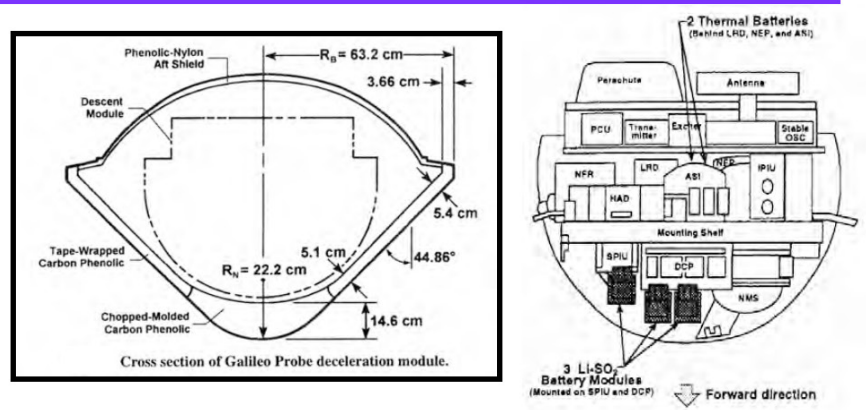

- Overall Challenge: What is the probe mass allocation amongst subsystems as we scale the probe?

- Deceleration Module

- TPS

- Descent Module

- Pressure Vessel mass - different than Galileo

- Other subsystems mass allocations are made but need to be validated with future refinement

Figure 8.-Galileo mission atmospheric probe mass summary (reprinted from Ref. 30 with permission). 

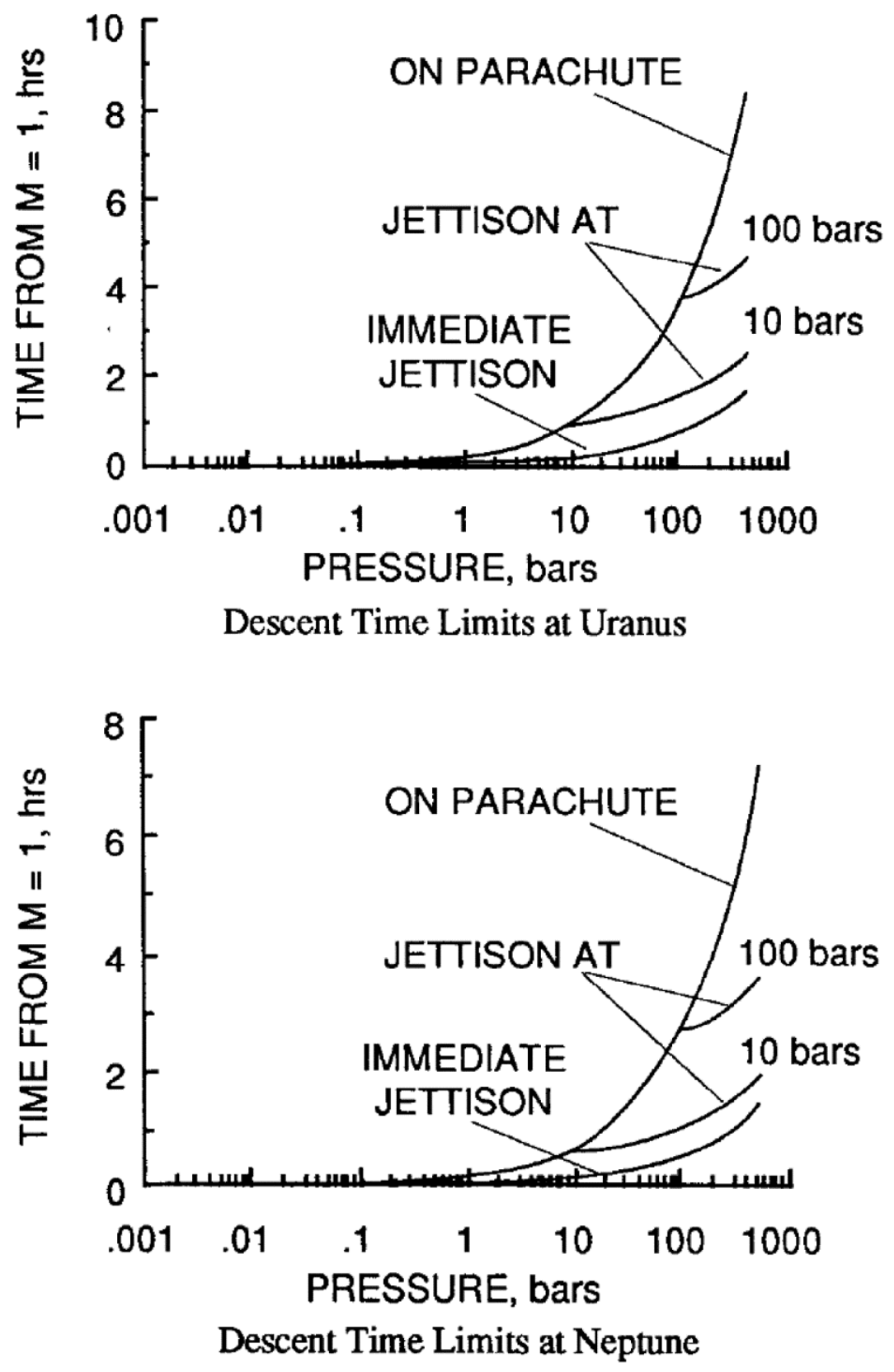

Figure 9.-Probe descent times for Uranus (upper) and Neptune (lower); descent time begins at Mach $=1.0$ (Ref. 32). From Deep Atmospheric Probe Missions to Uranus and Neptune, Byron L. Swenson et al.; reprinted by permission of the American Institute of Aeronautics and Astronautics, Inc. 


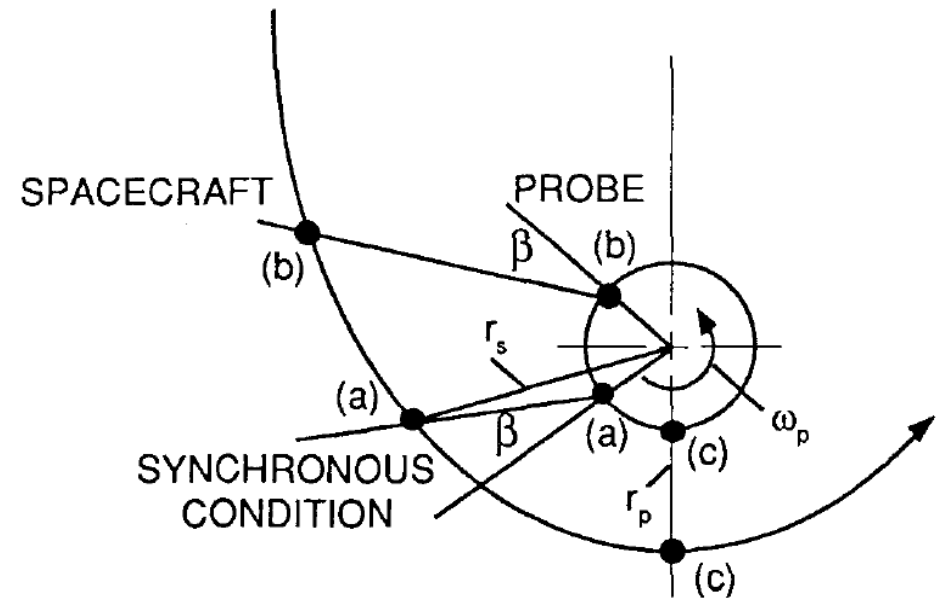

PERIAPSIS

Figure 10.-Probe and receiver (unmanned aerial vehicle (UAV) or aerospacecraft) data transmission visibility geometry (Ref. 32). From Deep Atmospheric Probe Missions to Uranus and Neptune, Byron L. Swenson et al; reprinted by permission of the American Institute of Aeronautics and Astronautics, Inc.

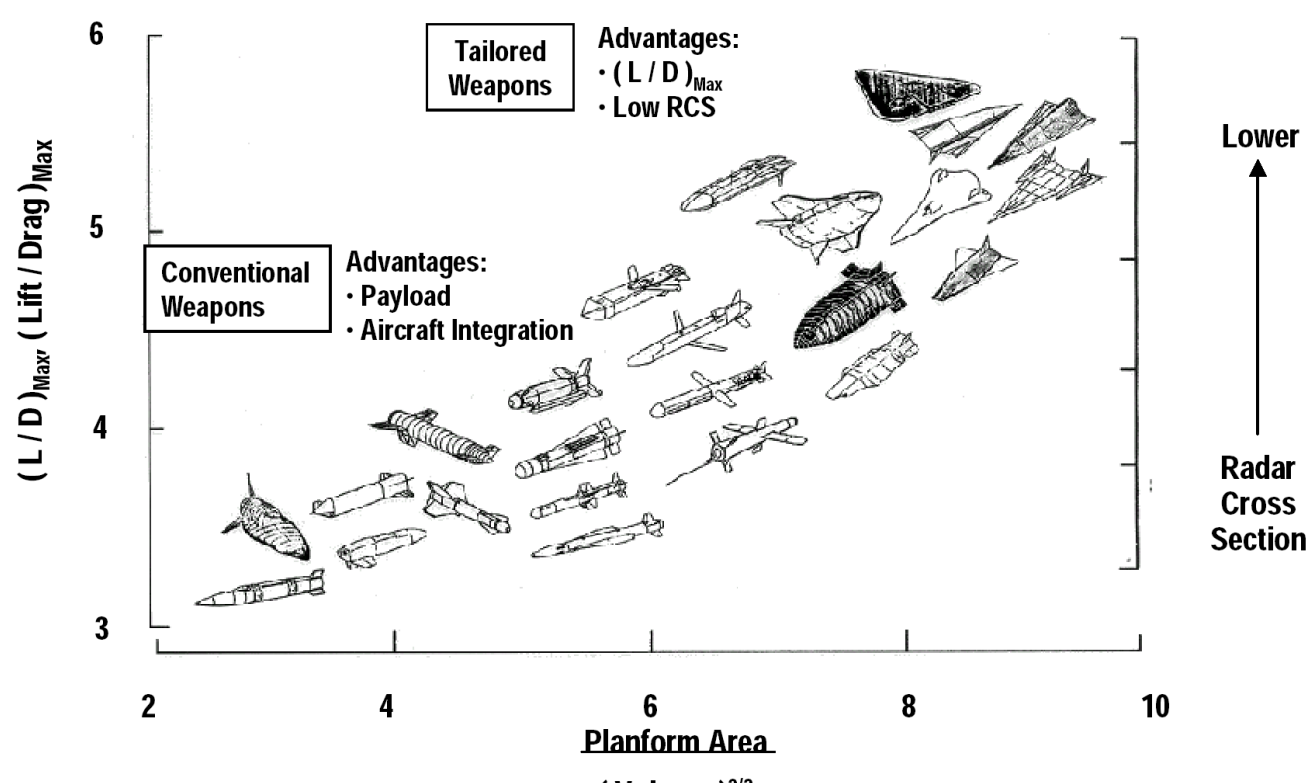

Figure 11.-_UAV configuration options (reprinted from Ref. 36 with permission). 


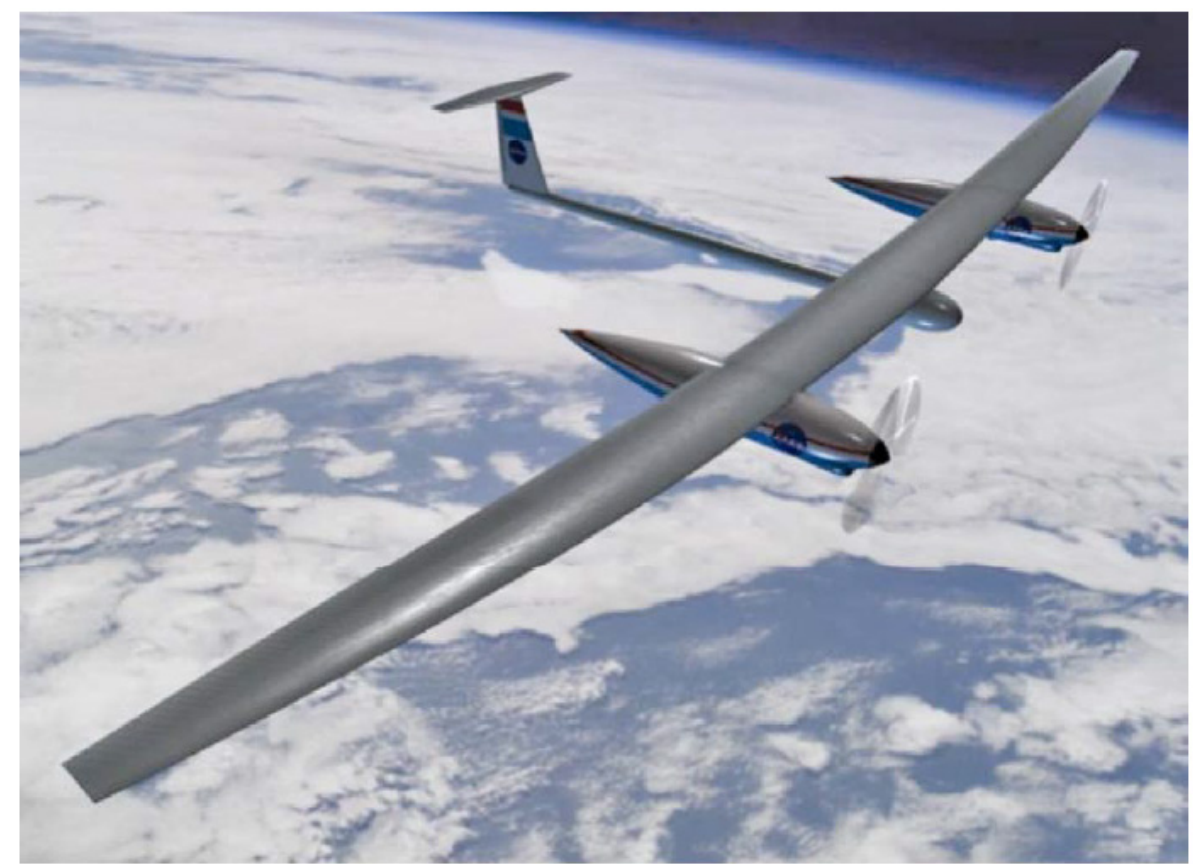

Figure 12.-Low-subsonic-speed-class UAV (Ref. 36).
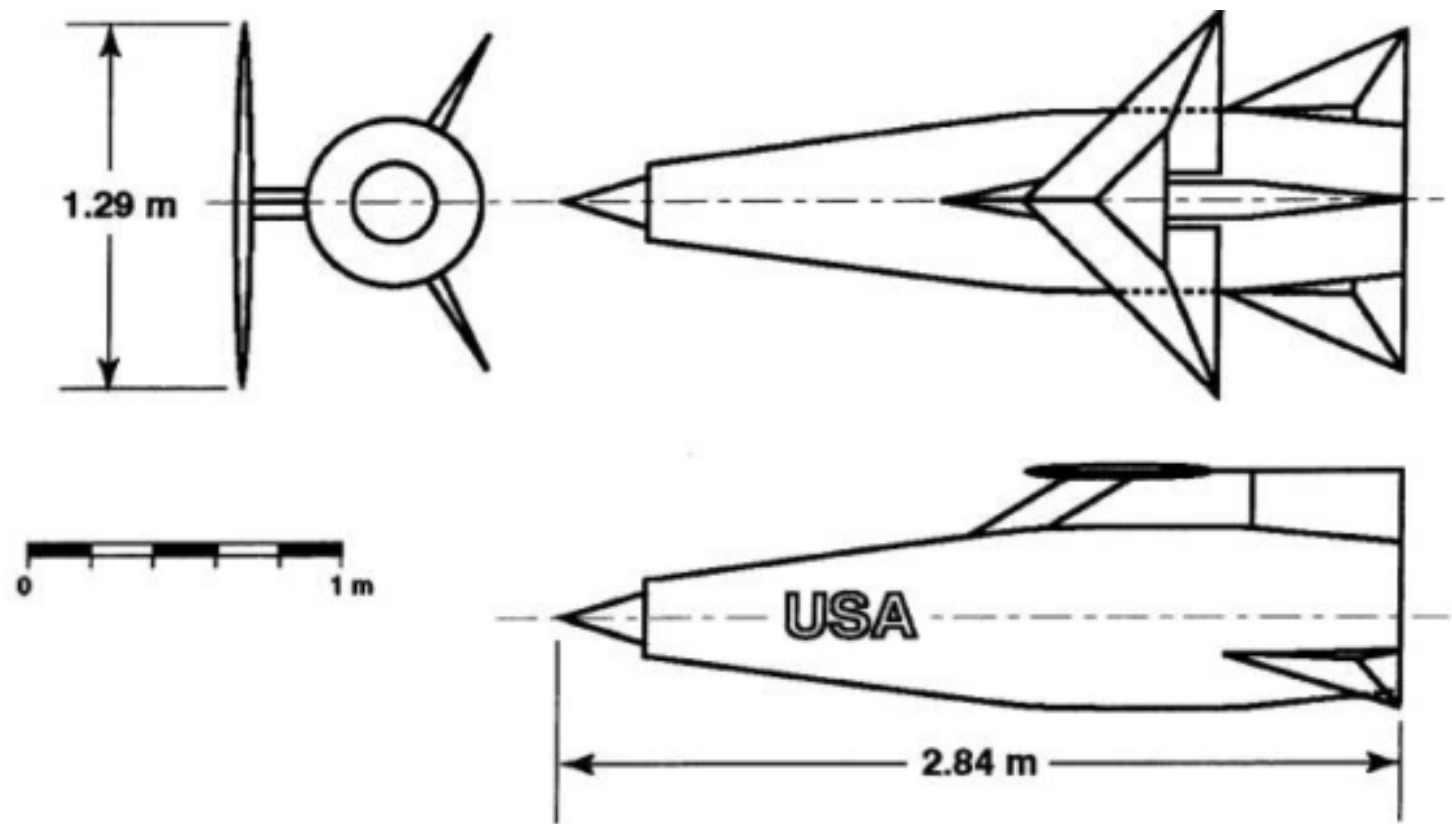

Figure 13.-Nuclear ramjet engine integrated into aircraft/UAV (Ref. 42). From Application of the MITEE Nuclear Ramjet for Ultra Long Range Flyer Missions in the Atmospheres of Jupiter and Other Giant Planets, George Maise et al.; reprinted by permission of the American Institute of Aeronautics and Astronautics, Inc. 


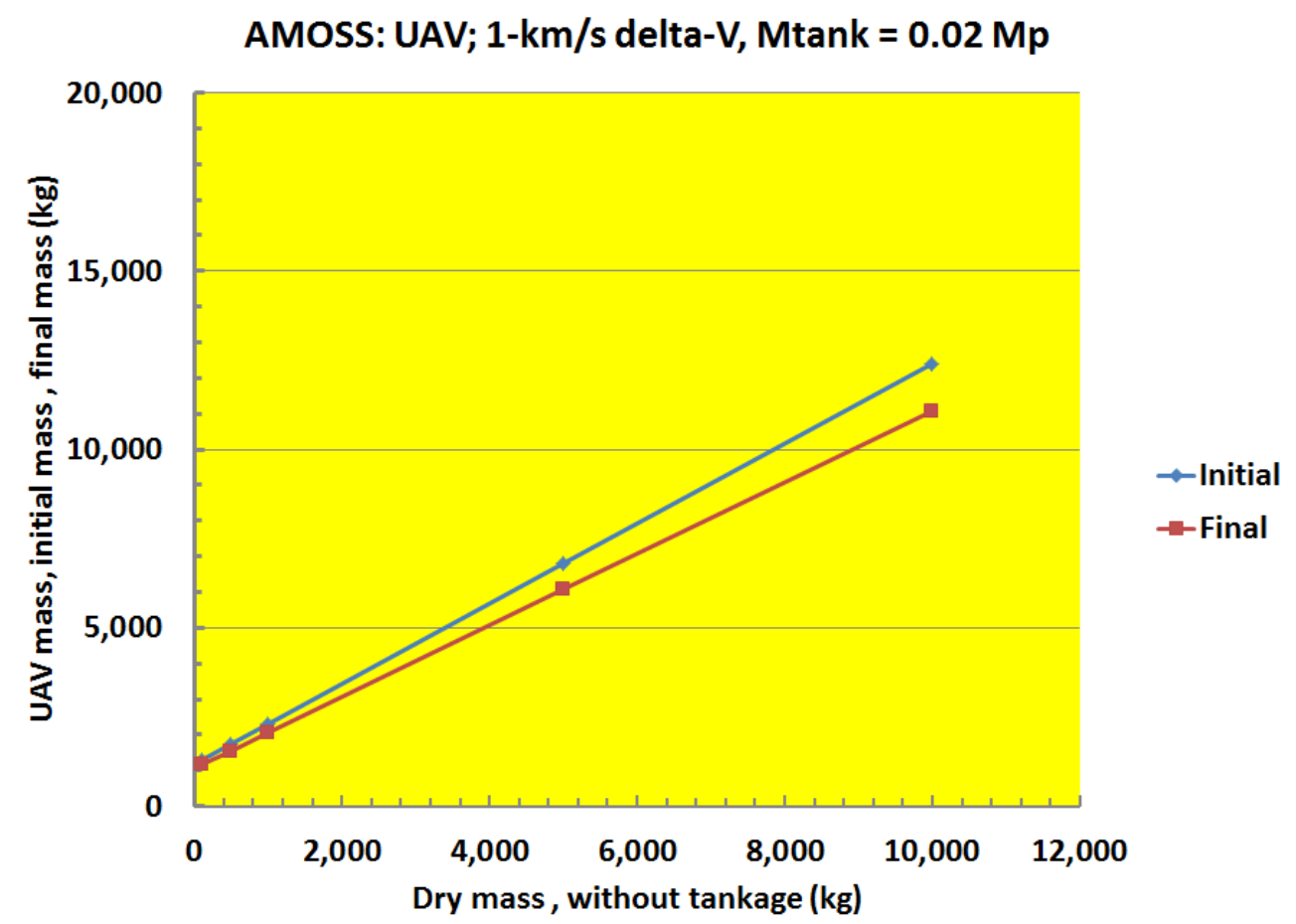

Figure 14.-Mass of UAV for atmospheric mining in the outer solar system (AMOSS) at $1 \mathrm{~km} / \mathrm{s}$ delta- $\mathrm{V}$ capability and $M_{\text {tank }}=0.02 M_{p}$.

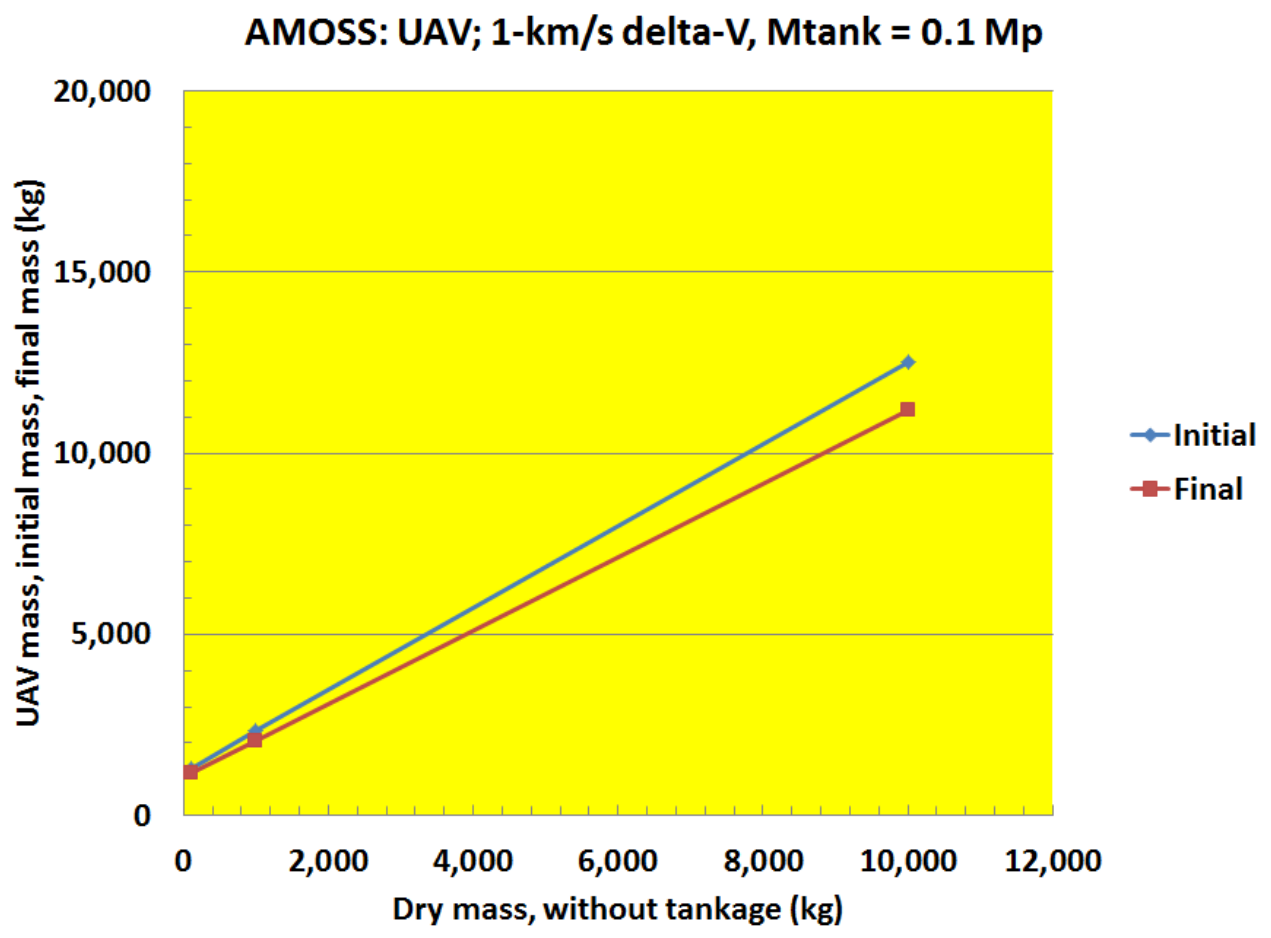

Figure 15.-Mass of UAV for AMOSS at $1 \mathrm{~km} / \mathrm{s}$ delta- $\mathrm{V}$ capability and $M_{\text {tank }}=0.1 \mathrm{Mp}_{\mathrm{p}}$. 


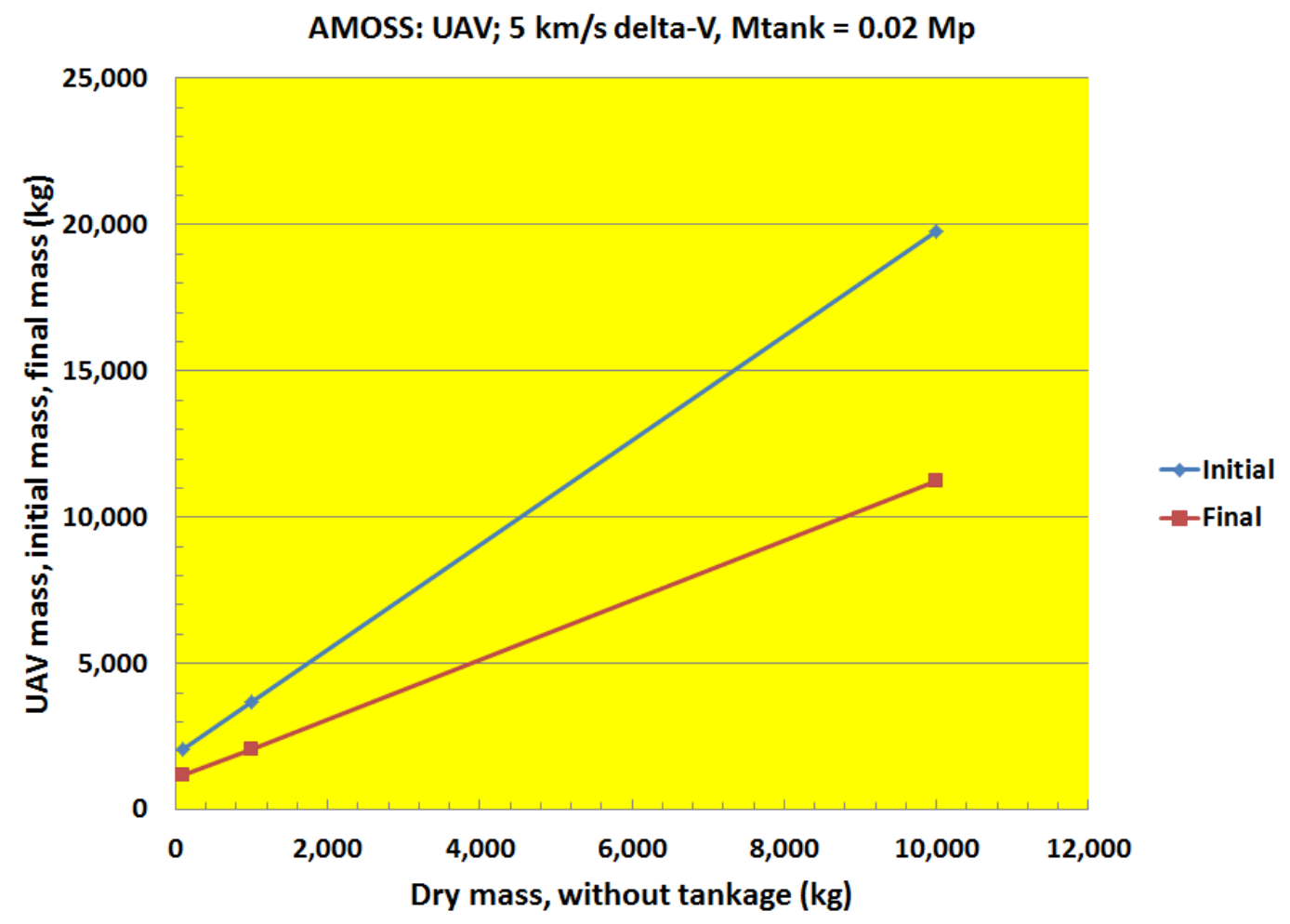

Figure 16.-Mass of UAV for AMOSS at $1 \mathrm{~km} / \mathrm{s}$ delta- $V$ capability and $M_{\text {tank }}=0.02 M_{\mathrm{p}}$.

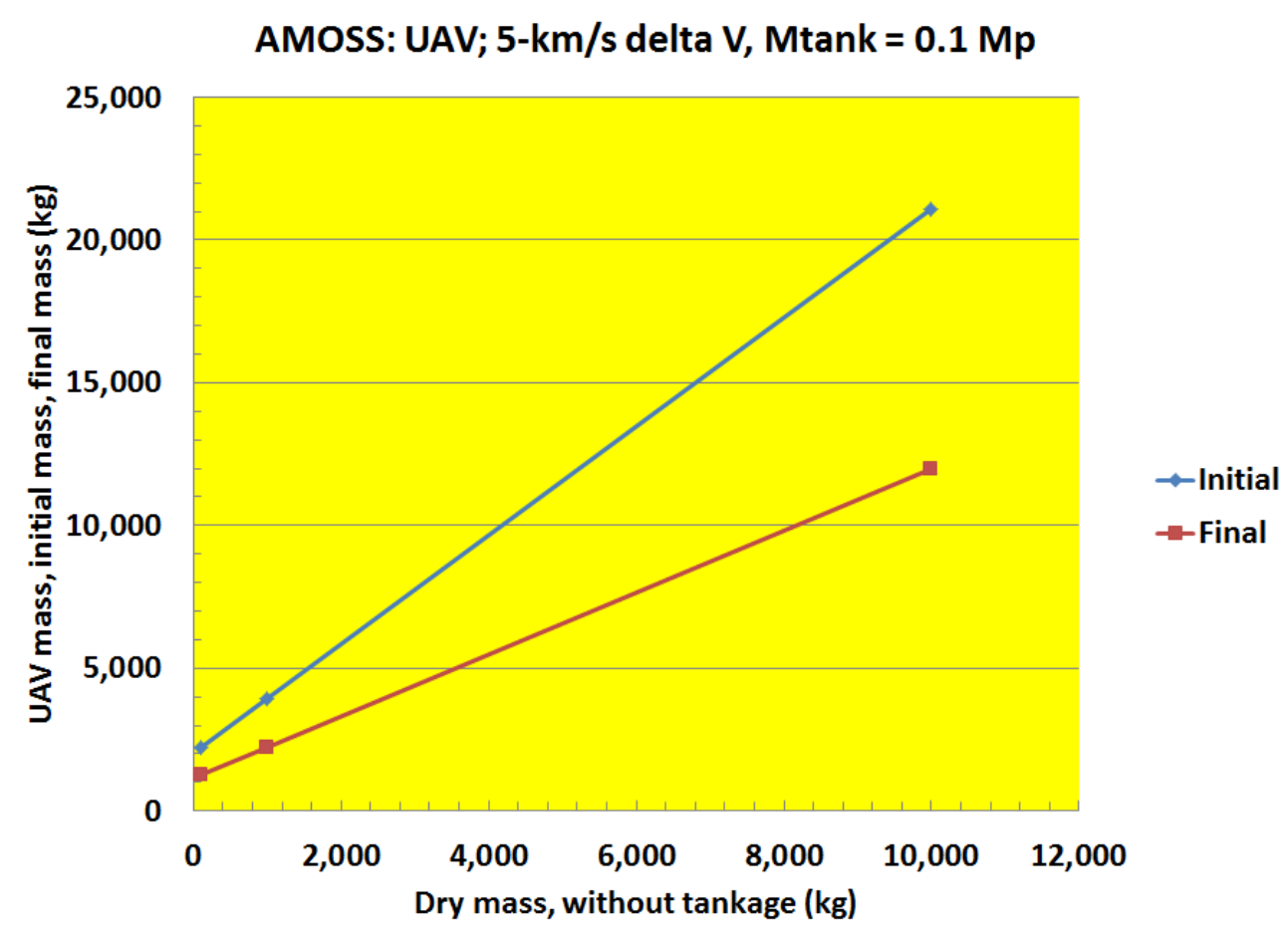

Figure 17.-Mass of UAV for AMOSS at $5 \mathrm{~km} / \mathrm{s}$ delta-V capability and $M_{\text {tank }}=0.1 M_{\mathrm{p}}$. 


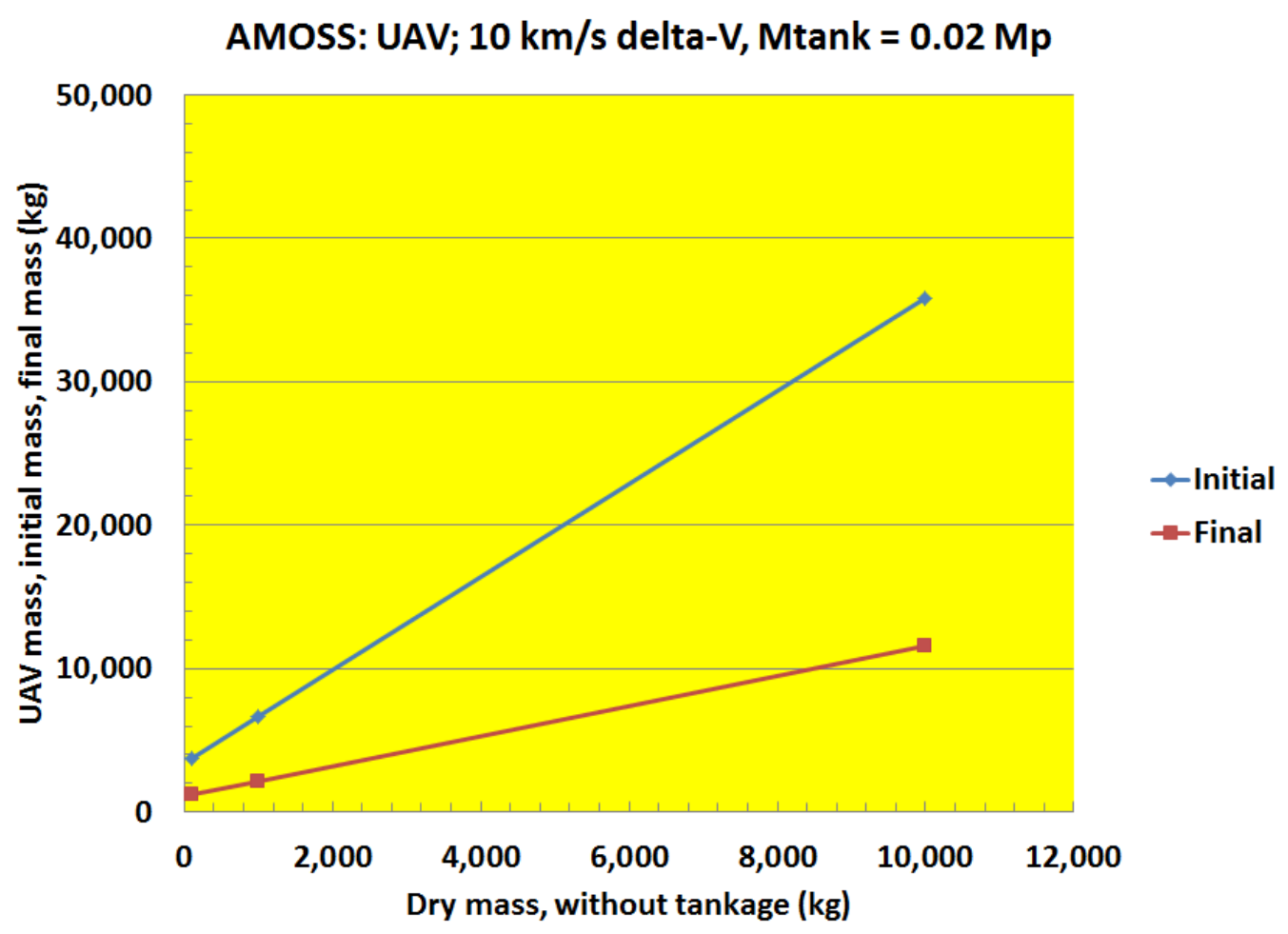

Figure 18. - Mass of UAV for AMOSS at $10 \mathrm{~km} / \mathrm{s}$ delta-V capability and $M_{\text {tank }}=0.02 M_{p}$.

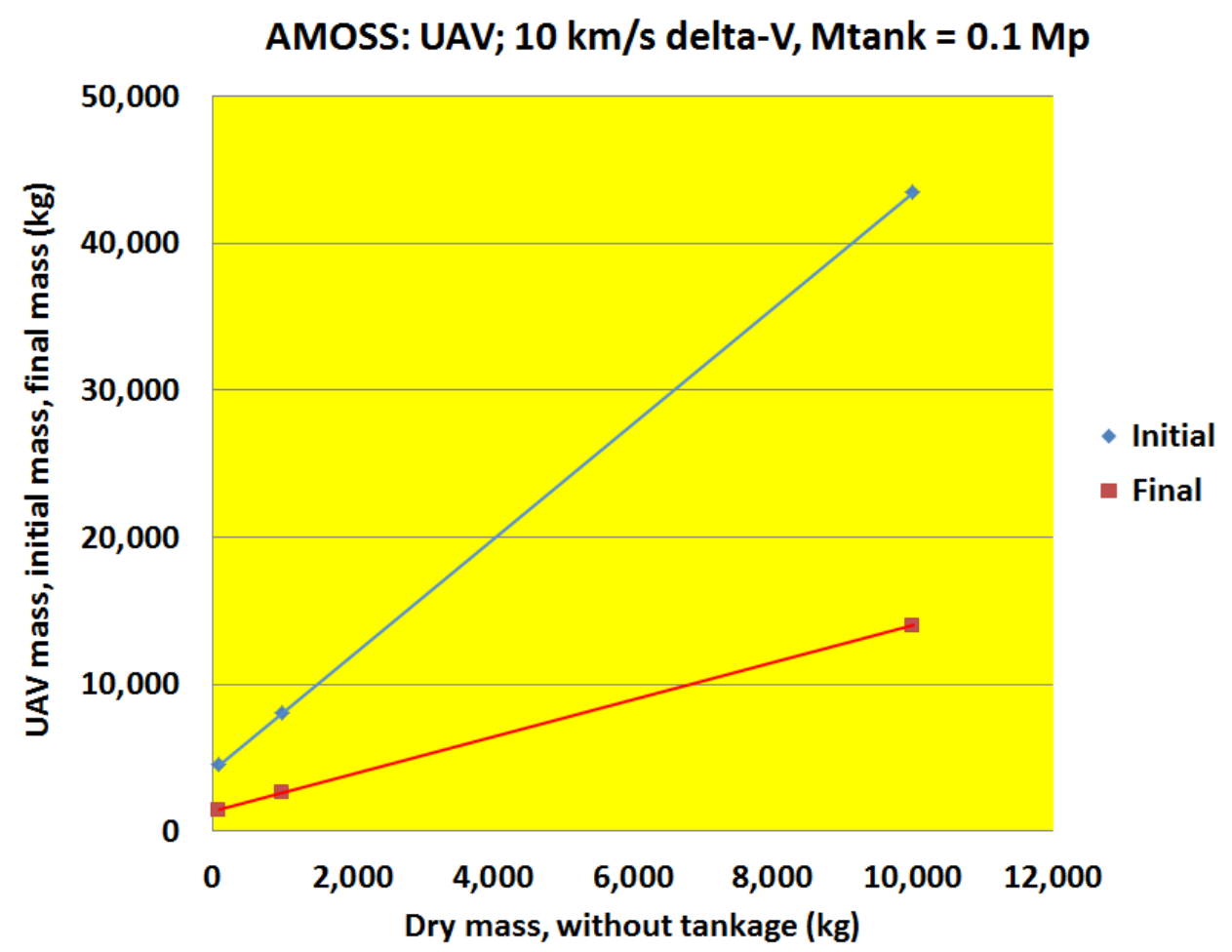

Figure 19.-Mass of UAV for AMOSS at $10 \mathrm{~km} / \mathrm{s}$ delta- $V$ capability and $M_{\text {tank }}=0.1 M_{p}$. 


\section{Appendix A.-Planet Data-Uranus and Neptune}

This appendix presents cloud images from Earth-based (Keck) and space-based (Hubble) telescopes and spacecraft (Voyager). Figure 20 to Figure 24 show the cloud changes over many years of observations.

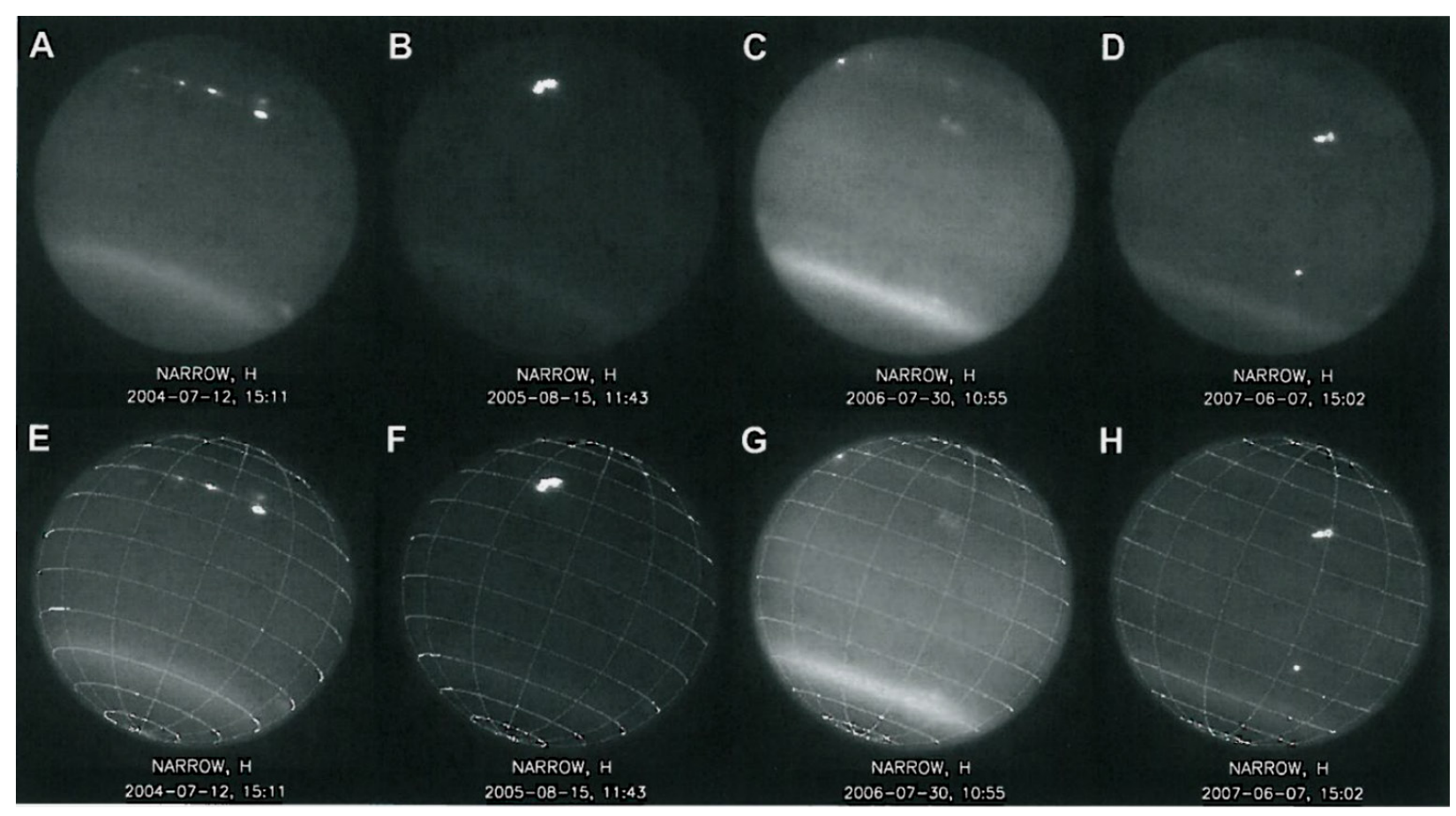

Figure 20.-Uranus cloud features (Keck II, Ref. 25). 
10 Nov 2011
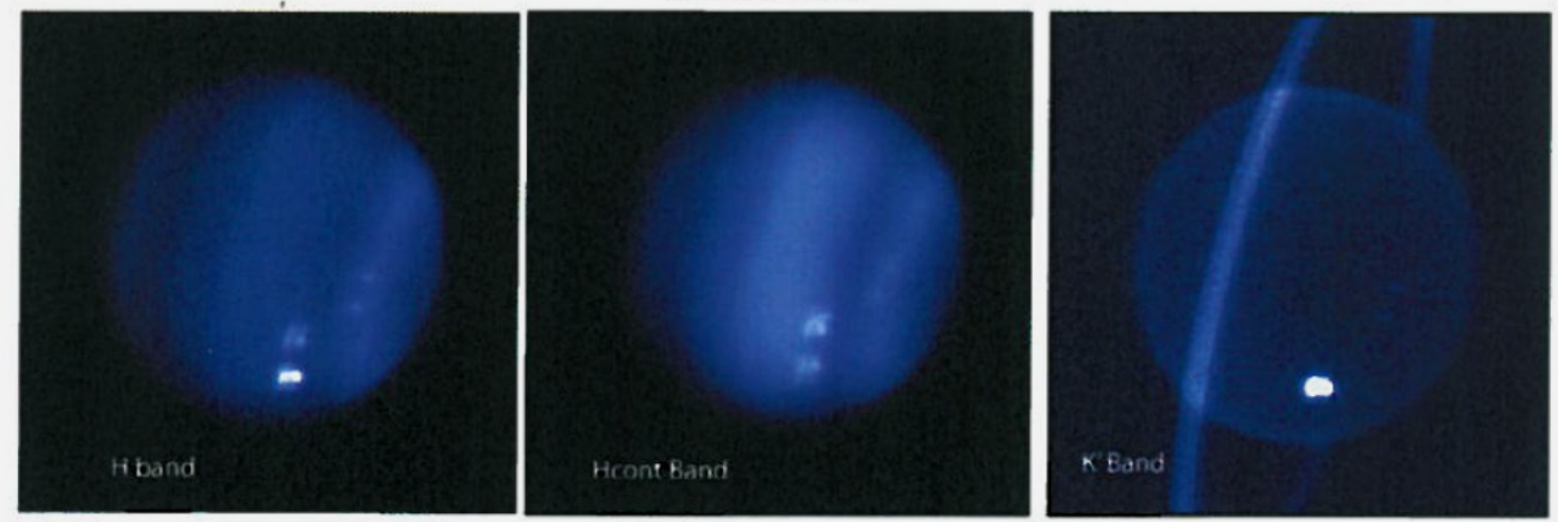

11 Nov 2011
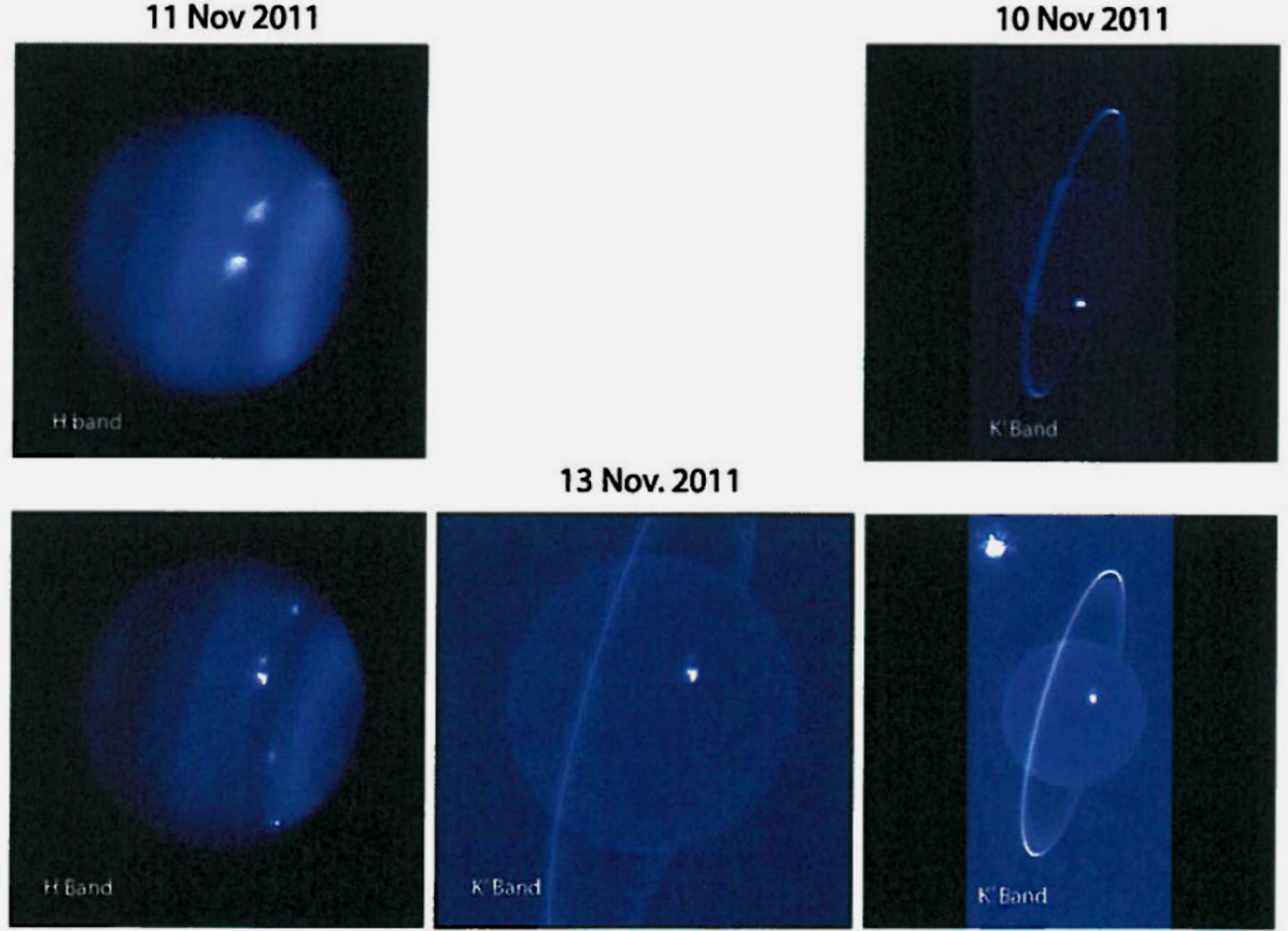

13 Nov. 2011

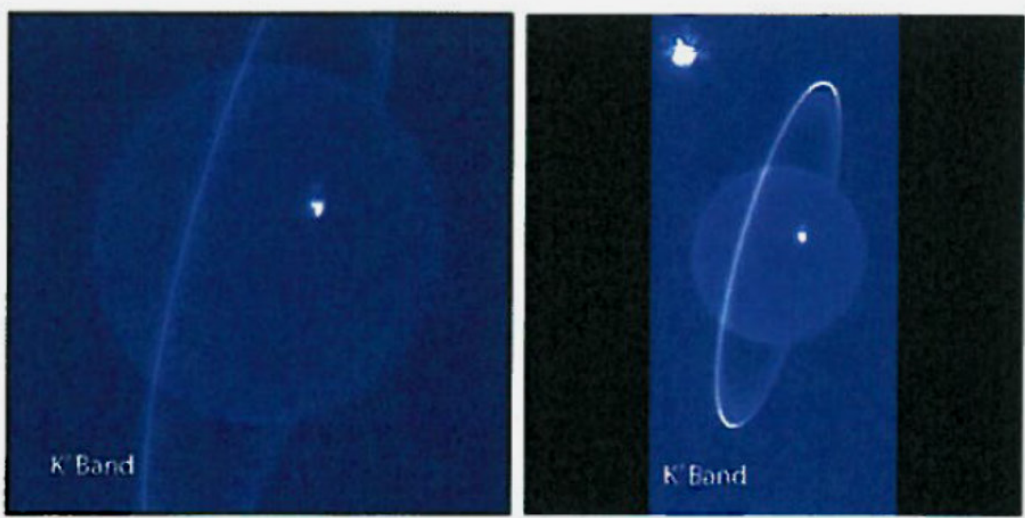

Figure 21.—Uranus cloud features and rings (Keck II, Ref. 25). 


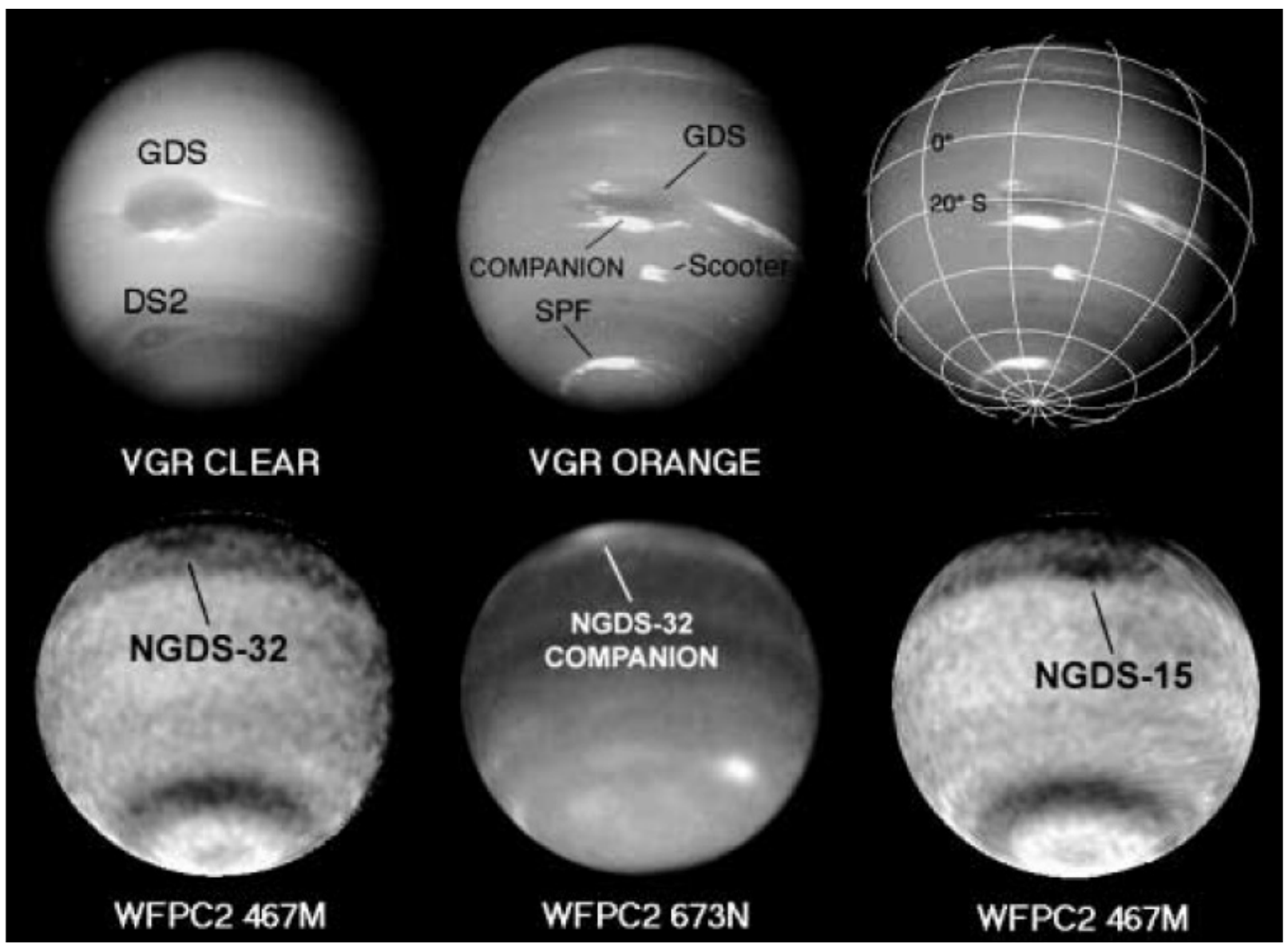

Figure 22.-Neptune cloud features (Voyager, Hubble, Ref. 27). ${ }^{1}$

${ }^{1}$ Reprinted from Icarus, vol. 156, no. 1, L.A. Sromovsky, P.M. Fry, and K.H. Baines, The Unusual Dynamics of Northern Dark Spots on Neptune, pp.16-36, 2002, with permission from Elsevier. 


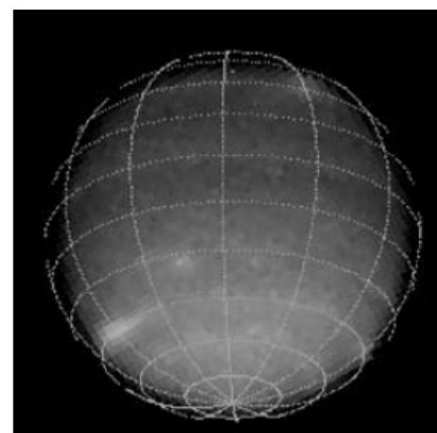

08:37:36 13/08/96

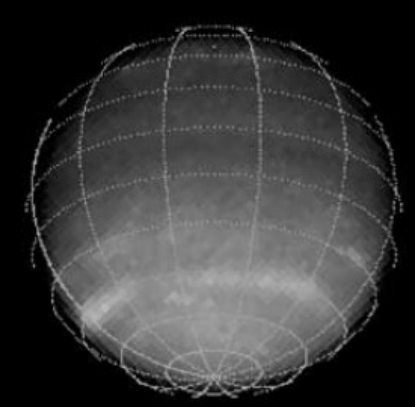

02:13:09 11/08/98

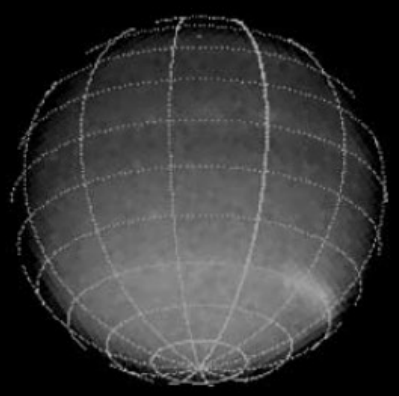

15:04:36 13/08/96

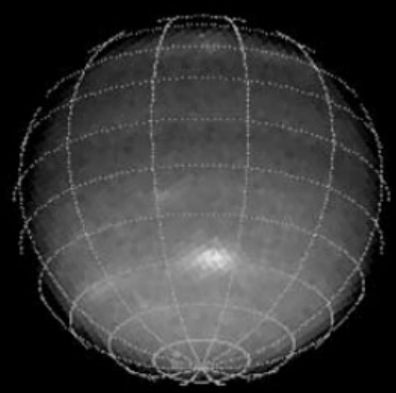

$21: 30: 36$ 13/08/96

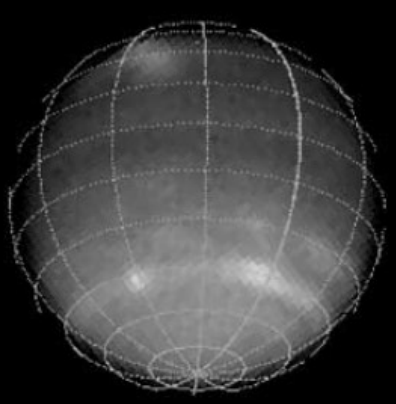

07:04:09 11/08/98

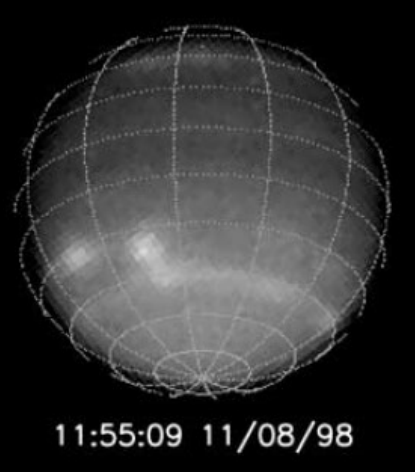

11:55:09 11/08/98

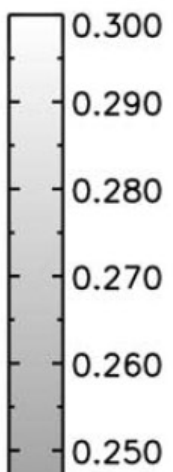

0.240

0.230

0.220

0.210

0.200

0.190

0.180

0.170

0.160

0.150

$11: 58: 142002-08-09$

16:50:14 2002-08-09

$15: 17: 142002-08-10$

Figure 23.-Neptune cloud features (Hubble, Ref. 26). ${ }^{2}$

${ }^{2}$ Reprinted from Icarus, vol. 163, L.A. Sromovsky et al., The Nature of Neptune's Increasing Brightness: Evidence for a Seasonal Response, pp. 256-261, 2003, with permission from Elsevier. 


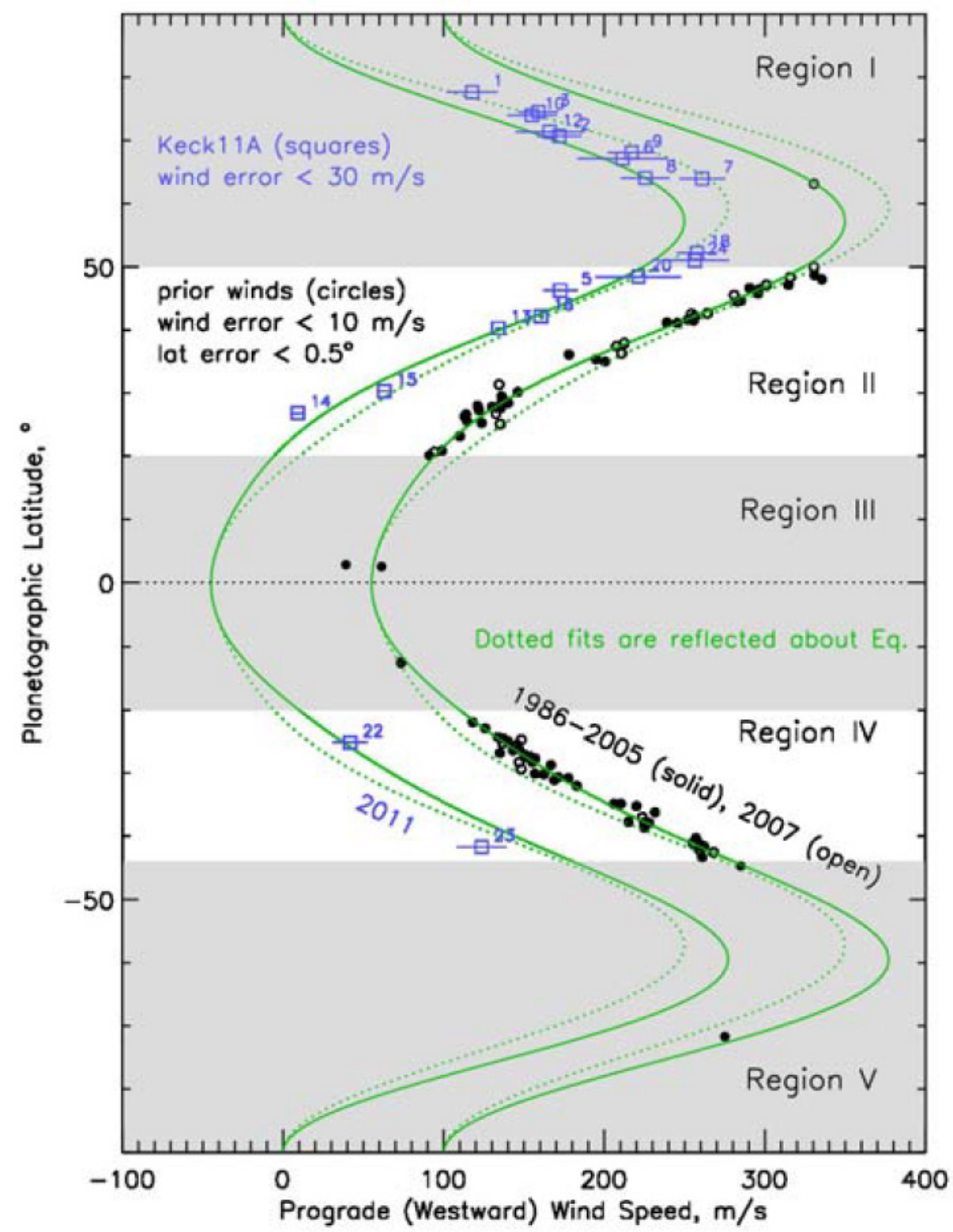

Figure 24.-UUranus winds velocities (from Ref. 43). 



\section{Appendix B.- Issues for Cryogenic Operations}

Cryogenic moons and operations on those bodies is important for outer-planet moon and planet exploration. Data for identifying the moons, their apparent densities, and the technological consideration in operations on those moons are presented in Figure 25 to Figure 28.

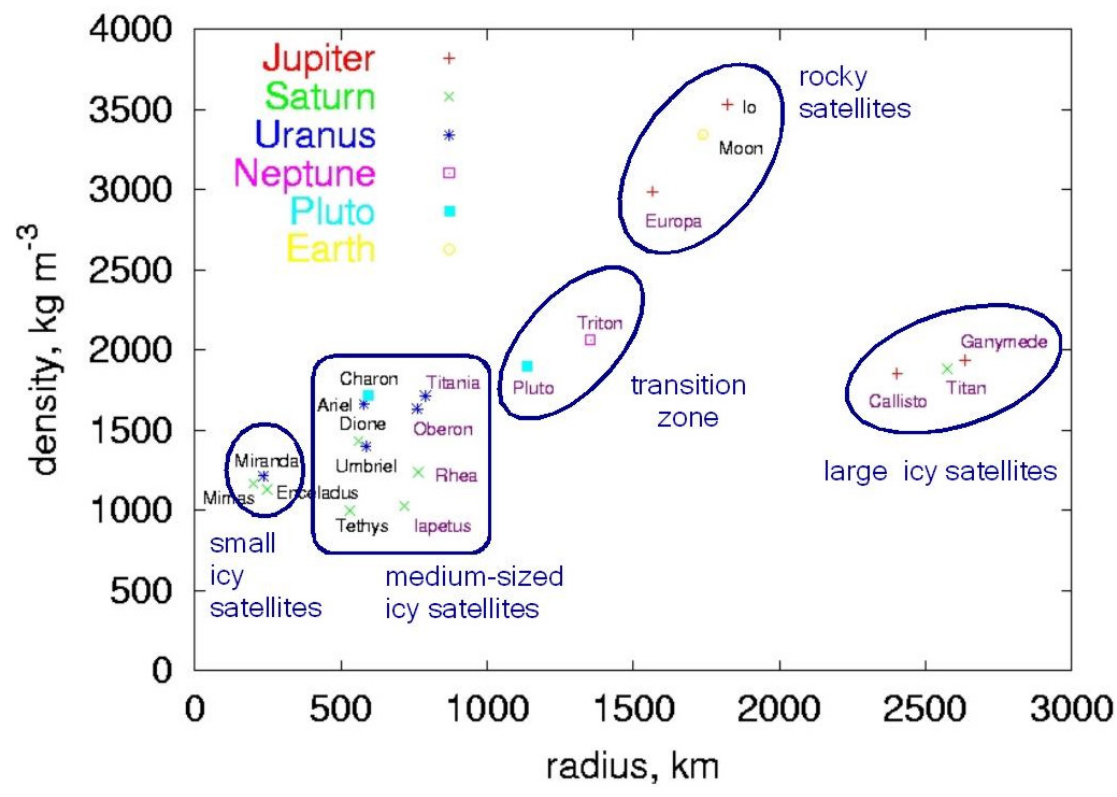

Figure 25.--Outer-planet moon densities (Ref. 44). ${ }^{3}$

\section{Moon Bases in Cryogenic Environments: Issues}

- Power sources

- Seals

- Rotating components

- Adhesives

- Flexible - inflatable surfaces

- Dust, ice characteristics

- Robots, for maintenance, etc.

- Warmth for, maintenance of astronauts

Figure 26.-Issues for cryogenic outer-planet moon surface operations (Revolutionary Aerospace Concepts (RASC), Human Outer Planet Exploration (HOPE) study, Ref. 45).

\footnotetext{
${ }^{3}$ Reprinted from Icarus, vol. 185, no. 1, Hauke Hussmann, Frank Sohl, and Tilman Spohn, Subsurface Oceans and Deep Interiors of Medium-Sized Outer Planet Satellites and Large Trans-Neptunian Objects., pp. 258-273, 2006, with permission from Elsevier
} 


\section{Atmosphere of Uranus: \\ K.A. Rages, H.B. Hammel, A.J. Friedson, Evidence for temporal change at Uranus' south polle, 2004}

- Flighthin in the oufer planeft atunospheres are based on flightht at allifudes where the atumosplheric pressurre is about 1 afunosphere.

- The charis notes that this altiturde implies fllying in the haze layer of Uranus.

- The issue of flightht in the haze layer should be investigated (effects on aerospacecrafth, mining efficiency, efc.).

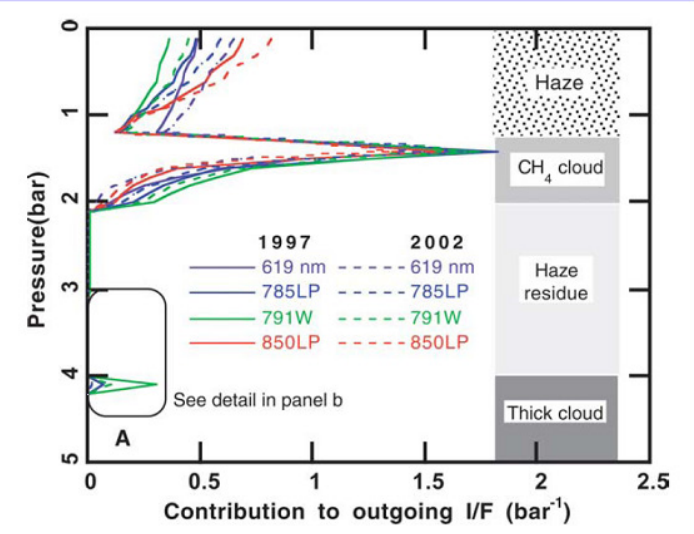

Figure 27.-Uranus atmospheric structure, haze phenomena (Ref. 46). ${ }^{4}$

\section{AMOSS: What's Next?}

- Daedalus Redux (British Interplanetary Society (BIS) Study, Martin, A., et al., 1979).

- More attention to atmospheric mining for starship fueling.

- Schedules of ISRU fuel deliveries.

- Effect on construction - iff ISIRU process slowed or speeded up?

- Daedalus study assumed fusion powered atmospheric transfer vehicles and aerostats for gathering helium 3 and deuterium from Jupiter's atmosphere.

- Move mining location to Uranus or Neptune.

- Recent studies of AMOSS (Palaszewski, et al. AIAA JPC 2005, 2006, 2007, 2008) have used nuclear thermal propulsion (NTP) aerospacecraft (cruiser aircraft) for fuel mining and orbital delivery.

- Is NTP effective as a propulsion option? Is fusion required?

- Development of micro-factories (or macro-factories, or nanofactories(?)) for ship assembly and non-fuel related construction.

- Tirme added for mano- or micro-factory versus macro-factory consturuction (tirne for assembling afoms and moleculles, lifterally...)

Figure 28.-Atmospheric mining issues.

${ }^{4}$ Reprinted from Icarus, vol. 172, K.A. Rages, H.B. Hammel, and A.J. Friedson, Evidence for Temporal Change at Uranus' South Pole, pp. 548-554, 2004, with permission from Elsevier. 


\section{Appendix C.-Gas and Shock Properties (85 Percent Hydrogen, 15 Percent Helium by Volume)}

Figure 29 and Figure 30 (Ref. 47) present normal shock properties for hydrogen-helium mixtures with velocities to $70 \mathrm{~km} / \mathrm{s}$.

INITIAL CONDITIONS AHEAD OF INCIDENT NORMAL SHOCK

IN $0.85 \mathrm{H}_{2}-0.15 \mathrm{He}$

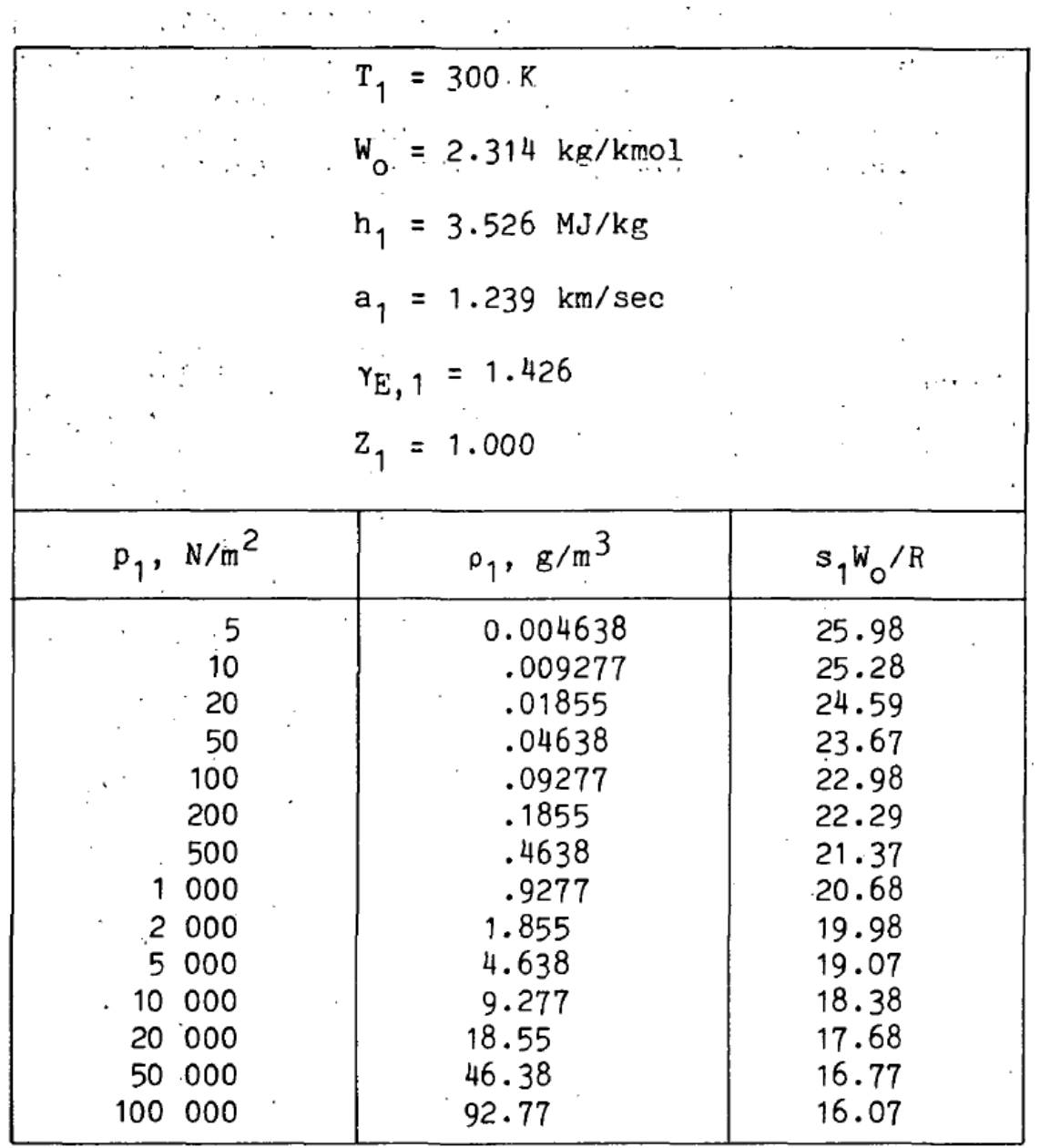

Figure 29.-Initial conditions ahead of incident normal shock in $0.85 \mathrm{H}_{2}-0.15 \mathrm{He}$ (Ref. 47). 


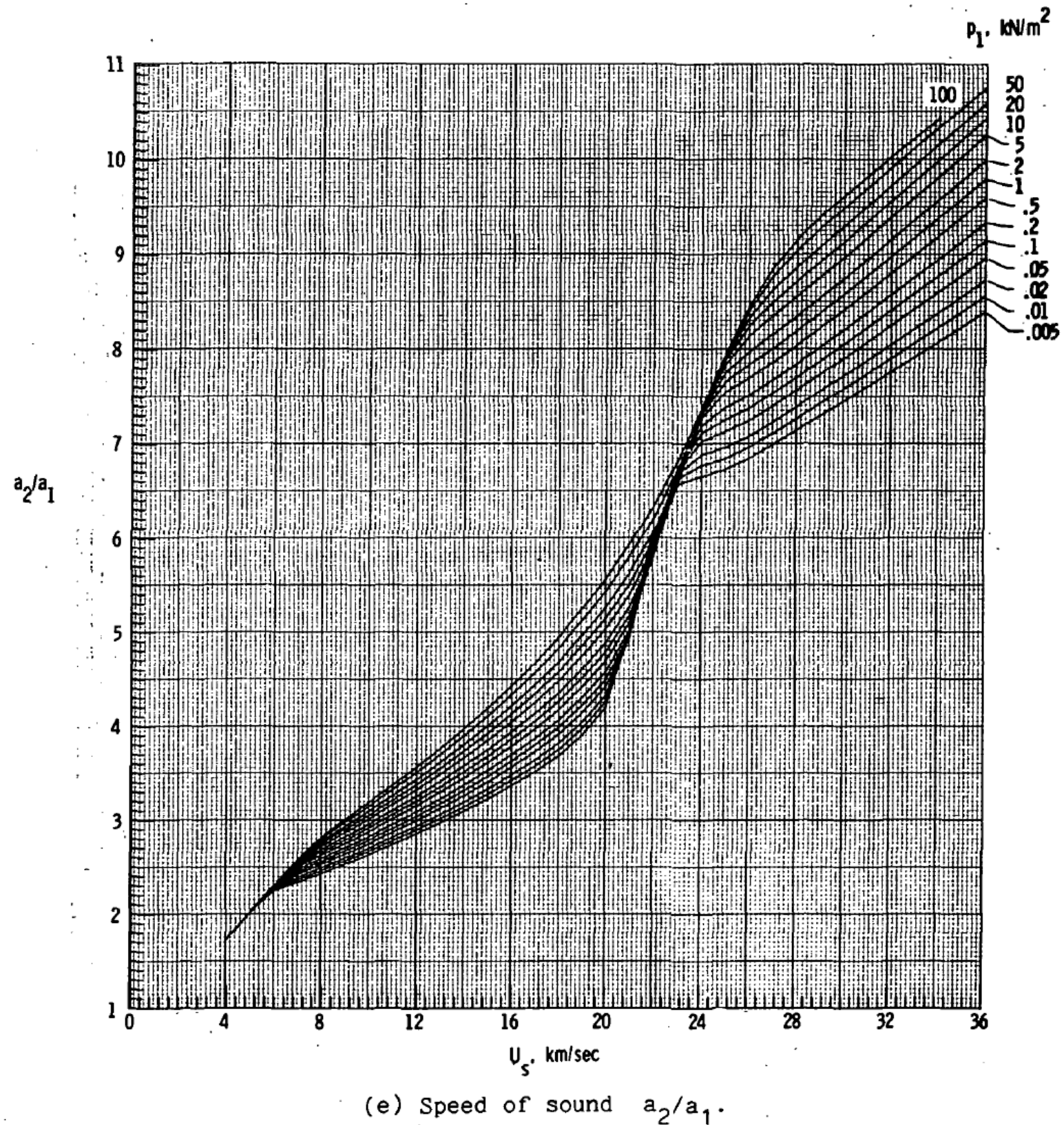

Figure 30.-Thermodynamic properties and flow velocity behind an incident normal shock into a $0.85 \mathrm{H}_{2}-0.15 \mathrm{He}$ mixture (Ref. 47). 


\section{Appendix D.-Detonation Engine Data}

The appendix presents detonation rocket engine performance in Figure 31 and Figure 32. This type of engine was proposed for flight in high-pressure atmospheric environments.

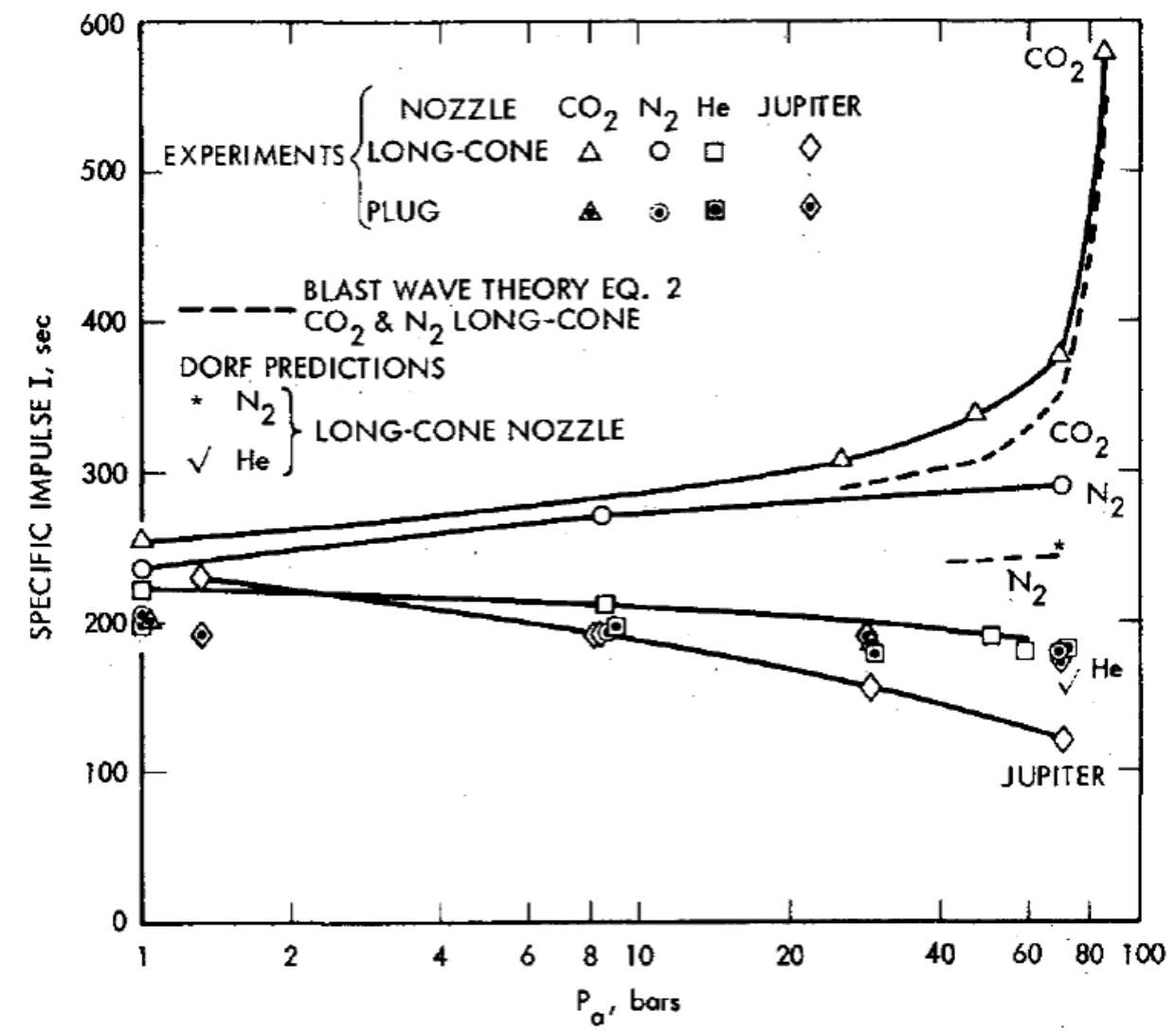

Figure 31.-Variation of specific impulse with ambient pressure for various ambient gases (carbon dioxide $\left(\mathrm{CO}_{2}\right)$, nitrogen $\left(\mathrm{N}_{2}\right)$, and helium $(\mathrm{He})$ ). with long-cone and firing-plug nozzles (Ref. 33). From Detonation Propulsion Experiments and Theory. Measurement of Detonation Propulsion in Helium and Performance Calculations, Lloyd H. Back, Warren L. Dowler, and Giulio Varsi; reprinted by permission of the American Institute of Aeronautics and Astronautics, Inc. 


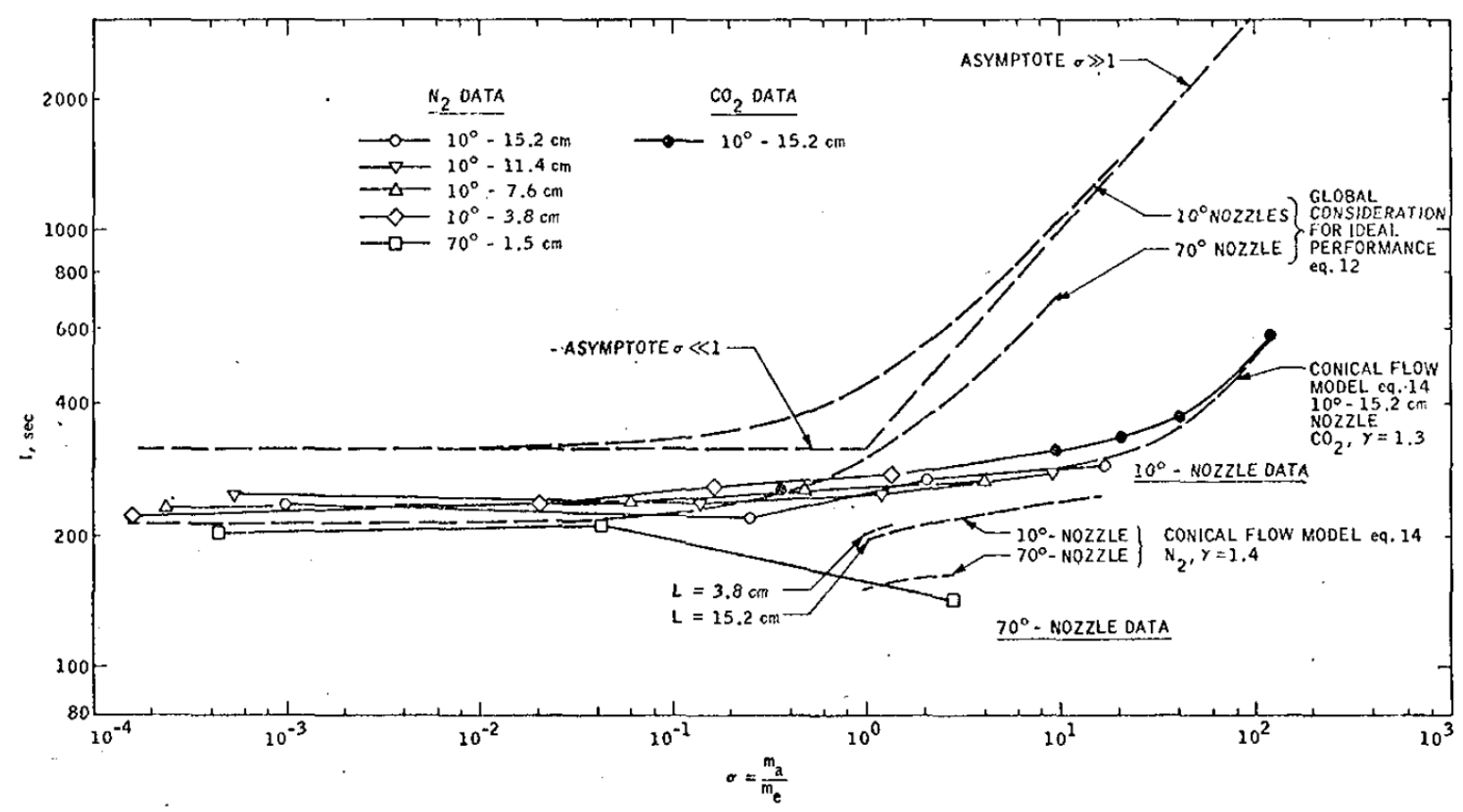

Figure 32.-Engine specific impulse, including high angle nozzles (Ref. 34). From Detonation Propulsion for High Pressure Environments, Giulio Varsi and Lloyd H. Back; reprinted by permission of the American Institute of Aeronautics and Astronautics, Inc. 


\section{References}

1. Palaszewski, Bryan: Atmospheric Mining in the Outer Solar System: Resource Capturing, Storage, and Utilization. AIAA 2012-3742, 2012.

2. Palaszewski, Bryan: Atmospheric Mining in the Outer Solar System: Issues and Challenges for Mining Vehicle Propulsion. AIAA 2011-6041, 2011.

3. Palaszewski, Bryan: Atmospheric Mining in the Outer Solar System: University Studies of Mining Vehicles and Propulsion. AIAA 2010-6573, 2010.

4. Palaszewski, Bryan: Atmospheric Mining in the Outer Solar System: Mining Design Issues and Considerations. AIAA 2009-4961, 2009.

5. Palaszewski, Bryan: Atmospheric Mining in the Outer Solar System: Orbital Transfer Vehicles and Outer Planet Moon Base Options. AIAA 2008-4861, 2008.

6. Palaszewski, Bryan: Atmospheric Mining in the Outer Solar System: Mission Scenarios and Options for In-Situ Resource Utilization. AIAA 2007-5598, 2007.

7. Palaszewski, Bryan: Atmospheric Mining in the Outer Solar System: Vehicle Sizing Issues. AIAA 2006-5222, 2006.

8. Palaszewski, Bryan: Atmospheric Mining in the Outer Solar System. AIAA 2005-4319, 2005.

9. Frisbee, Robert: Advanced Space Propulsion for the 21st Century. J. Propul. P., vol. 19, no. 6, 2003.

10. Dunn, Bruce P.: High-Energy Orbit Refueling for Orbital Transfer Vehicles. J. Spacecr. Rockets, vol. 24 , no. 6,1987 , pp. $518-522$.

11. Noca, Muriel; and Polk, James E.: Ion Thrusters and LFAs for Outer Planet Exploration. Presented at the AAF 6th International Symposium on Propulsion for Space Transportation of the XXIst Century, paper no. 228, Versailles, France, 2002.

12. Hunt, James L.; Laruelle, Gerard; and Wagner, Alain: Systems Challenges for Hypersonic Vehicles. AGARD Future Aerospace Technology in Service to the Alliance Conference, AGARD Paper C37 (NASA TM-112908), 1997. http://ntrs.nasa.gov

13. Starr, Brett R.; Westhelle, Carlos H.; and Masciarelli, James P.: Aerocapture Performance Analysis for a Neptune-Triton Exploration Mission. AIAA 2004-4955, 2004.

14. Bussard, R.W.: ASPEN 2: Two-Staging and Radiation Shielding Effects on ASPEN Vehicle Performance. LA-2680, 1962. http://ntrs.nasa.gov

15. Bussard, Robert W.; and Jameson, Lorin W.: The QED Engine Spectrum: Fusion-Electric Propulsion for Air-Breathing to Interstellar Flight. AIAA 93-2006, 1993.

16. Borowski, Stanley K.; Dudzinski, Leonard A.; and McGuire, Melissa L.: Artificial Gravity Vehicle Design Option for NASA's Human Mars Mission Using "Bimodal” NTR Propulsion. AIAA-99$2545,1999$.

17. Kendall, J.S.; and Stoeffler, R.C.: Conceptual Design Studies and Experiments Related to Cavity Exhaust Systems for Nuclear Light Bulb Configurations. (NASA-CR-129298), 1972. http://ntrs.nasa.gov

18. Latham, Thomas S.; and Rodgers, Richard J.: Small Nuclear Light Bulb Engines With Cold Beryllium Reflectors. AIAA Paper No. 72-1093, 1972.

19. Latham, Thomas S.: Summary of the Performance Characteristics of the Nuclear Light Bulb Engine. AIAA Paper No. 71-642, 1971.

20. Rodgers, R.J.; and Latham, T.S.: Analytical Design and Performance Studies of the Nuclear Light Bulb Engine. United Aircraft Corporation Report No. L-910900-16 (NASA CR-129295), 1972.

21. Sromovsky, L.A., et al.: Uranus at Equinox: Cloud Morphology and Dynamics. Icarus, vol. 203, no. 1, 2009, pp. 265-286.

22. Sromovsky, L.A.; and Fry, P.M.: The Methane Abundance and Structure of Uranus' Cloud Bands Inferred From Spatially Resolved 2006 Keck Grism Spectra. Icarus, vol. 193, no. 1, 2008, pp. 252-266.

23. Hammel, H.B., et al.: The Dark Spot in the Atmosphere of Uranus in 2006: Discovery, Description, and Dynamical Simulations. Icarus, vol. 201, no. 1, 2009, pp. 257-271.

24. Sromovsky, Lawrence: Investigating Atmospheric Change on Uranus and Neptune. University of Wisconsin-Madison, Madison, WI, 2012. 
25. Sromovsky, L.A., et al.: Episodic Bright and Dark Spots on Uranus. Icarus, vol. 220, no. 1, 2012, pp. 6-22.

26. Sromovsky, L.A., et al.: The Nature of Neptune's Increasing Brightness: Evidence for a Seasonal Response. Icarus, vol. 163, 2003, pp. 256-261.

27. Sromovsky, L.A.; Fry, P.M.; and Baines, K.H.: The Unusual Dynamics of Northern Dark Spots on Neptune. Icarus, vol. 156, no. 1, 2002, pp.16-36.

28. Sromovsky, L.A., et al.: Neptune's Atmospheric Circulation and Cloud Morphology: Changes Revealed by 1998 HST Imaging. Icarus, vol. 150, 2001, pp. 244-260.

29. Sromovsky, Lawrence A.; Limaye, Sanjay S.; and Fry, Patrick M.: Clouds and Circulation on Neptune: Implications of 1991 HST Observations. Icarus, vol. 118, no. 1, 1995, pp. 25-38.

30. Wercinski, P., et al.: Outer Planet Probe Design-Entry System Challenges. 3rd International Planetary Probe Workshop, Anavyssos, Greece, 2005.

31. Young, Richard E.: The Galileo Probe Mission to Jupiter: Science Overview. J. Geoph. Res., vol. 103, no. E10, 1998, pp. 22775-22790.

32. Swenson, Byron L., et al.: Deep Atmospheric Probe Missions to Uranus and Neptune. AIAA-902893-CP, 1990.

33. Back, Lloyd H.; Dowler, Warren L.; and Varsi, Giulio: Detonation Propulsion Experiments and Theory. AIAA J., 1983, vol. 21, no. 10, pp. 1418-1427.

34. Varsi, Giulio; and Back, Lloyd H.: Detonation Propulsion for High Pressure Environments. AIAA Paper No. 73-1237, 1973.

35. Kim, K.; Back, L.H.; and Varsi, G.: Measurement of Detonation Propulsion in Helium and Performance Calculations. AIAA J., vol. 14, no. 3, pp. 310-312.

36. Fleeman, E.L.; Berglund, E.; and Licata, W.H.: Technologies for Future Precision Strike Missile Systems (les Technologies des futurs systemes de missiles pour frappe de precision). RTO Lecture Series 221 bis., SCI-087, RTO-EN-018 AC/323(SCI-087 bis)TP/37, North Atlantic Treaty Organization Science and Technology Organization, 2001.

37. Millis, Marc G., et al.: Hydrogen Fuel System Design Trades for High-Altitude Long-Endurance Remotely-Operated Aircraft. NASA/TM-2009-215521, 2009. http://ntrs.nasa.gov

38. Borowski, S.: Robotic Planetary Science Missions Enabled With Small NTR Engine/Stage Technologies. NASA TM-107094, 1996. http://ntrs.nasa.gov

39. Maise, George, et al.: Exploration of Jovian Atmosphere Using Nuclear Ramjet Flyer. IAF Paper 98S608, 1998.

40. Powell, James, et al.: MITEE — An Ultra Lightweight Nuclear Engine for New and Unique Planetary Science and Exploration Missions. IAF Paper 98-R101, 1998.

41. Powell, James; Maise, George; and Paniagua, John: Nuclear Propulsion and Power Systems for Near Term Exploration of the Solar System. AIAA 2005-2597, 2005.

42. Maise, George, et al.: Application of the MITEE Nuclear Ramjet for Ultra Long Range Flyer Missions in the Atmospheres of Jupiter and Other Giant Planets. IAC-03-Q.4.09, 2003.

43. Sromovsky, Lawrence: Investigating Atmospheric Change on Uranus and Neptune. Award No. NNX08AO51G, 2012.

44. Hussmann, Hauke; Sohl, Frank; and Spohn, Tilman: Subsurface Oceans and Deep Interiors of Medium-Sized Outer Planet Satellites and Large Trans-Neptunian Objects. Icarus, vol. 185, no. 1, pp. 258-273.

45. Troutman, Patrick A., et al.: Revolutionary Concepts for Human Outer Planet Exploration (HOPE). Space Technology \& Applications International Forum, Albuquerque, NM, 2003.

46. Rages, K.A.; Hammel, H.B.; and Friedson, A.J.: Evidence for Temporal Change at Uranus' South Pole. Icarus, vol. 172, 2004, pp. 548-554.

47. Miller III, Charles G.; and Wilder, Sue E.: Table and Charts of Equilibrium Normal-Shock Properties for Hydrogen-Helium Mixtures With Velocities to $70 \mathrm{~km}-\mathrm{sec}$. Vol. 3, $85 \mathrm{H} 2$ - $15 \mathrm{He}$ (By Volume). NASA SP-3085, 1976. 



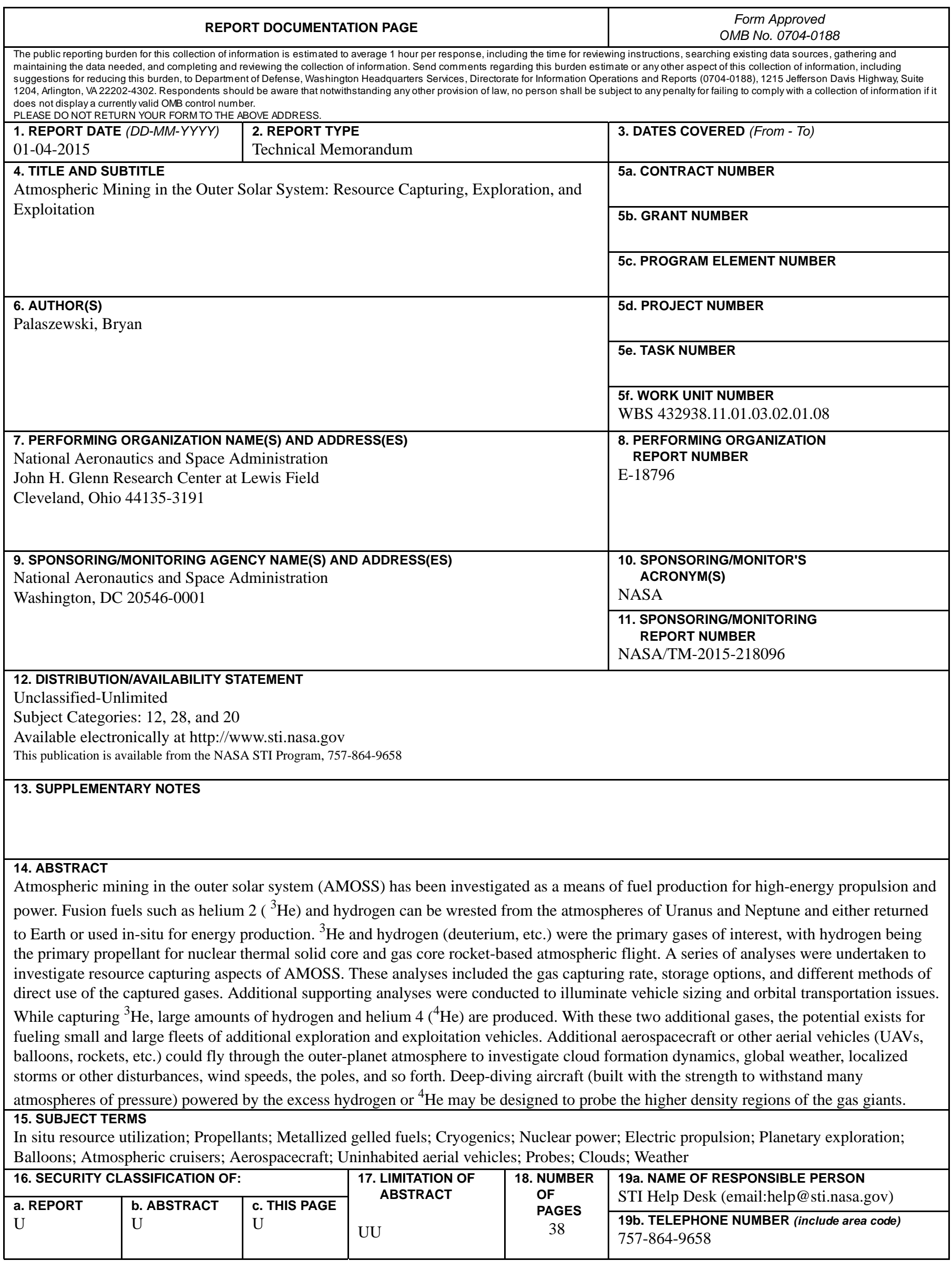



